\title{
SMART REGULATION AND FEDERALISM FOR THE SMART GRID
}

\author{
Joel B. Eisen*
}

\begin{abstract}
This Article examines the "Smart Grid," a set of concepts, technologies, and operating practices that may transform America's electric grid as much as the Internet has done, redefining every aspect of electricity generation, distribution, and use. While the Smart Grid's promise is great, this Article examines numerous key barriers to its development, including early stage resistance, a lack of incentives for consumers, and the adverse impacts of the federal-state tension in energy regulation. Overcoming these barriers requires both new technologies and transformative regulatory change, beginning with the development of a foundation of interoperability standards (rules of the road governing interactions on the Smart Grid) that will influence development for many years. This Article describes the federally coordinated standard-setting process started in the 2007 Energy Independence and Security Act, leading to a collaborative dialogue among hundreds of participants, with leadership from the National Institute of Standards and Technology ("NIST"). After setting forth the need for interoperability standards and elaborating on the standard-setting process, the Article focuses on a 2011 order by the Federal Energy Regulatory Commission ("FERC") that declined to adopt an initial group of standards. While this may appear a step backward, the Article argues to the contrary, finding that FERC's order supports the flexibility of the Smart Grid Interoperability Panel, the NIST-led process that will produce interoperability standards critical to a wide range of energy saving technologies. FERC's order allows this process, not a regulator's imprimatur, to give standards credibility. By holding off on forcing adoption of the standards, but preserving the potential for more significant federal intervention later, it may lead to state adoption of the resulting standards. In this adaptive approach to energy law federalism, neither top-down federal regulation nor private sector standard setting is the exclusive means of overseeing Smart Grid development. FERC's approach may promote a more positive federal-state relationship in the development of the Smart Grid, and may even portend a more collaborative relationship in energy law federalism generally, avoiding the disruptive jurisdictional clashes that have marked recent attempts to innovate in the electric grid.
\end{abstract}

Introduction .........................................



A. Operational Improvements for a More Efficient Grid ....... 8

B. Disruptive Consumer Applications ................ 10

II. Key Barriers to Smart Grid Development................ 13

A. Utilities Lack Incentives to Innovate................. 14

B. Consumers Know Little About the Smart Grid and Face High Transaction Costs in Translating Interest Into Action ........

C. Privacy Concerns Present As-Yet Unresolved Challenges ....

D. State PUCs Have Resisted Approving Smart Grid

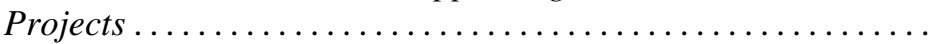

* Professor of Law, University of Richmond School of Law. Jim Rossi, Joseph Tomain, Katrina Kuh, and Michael Vandenbergh provided helpful comments. The author thanks the numerous federal and state regulators, practitioners, project directors, and academics with whom he met for their time and valuable insights. Special thanks are due to Suedeen Kelly, former FERC Commissioner and current Smart Grid Federal Advisory Committee member, for sharing her time and insights on the standards development process. Students and faculty at the Johns Hopkins University Energy Policy and Climate Program, Vanderbilt Law School, Harvard Law School, Harvard Kennedy School of Government, and University of Houston Law School contributed useful feedback. My colleagues Kristen Osenga, Bill Fisher, and Corinna Lain gave support and useful insights, and students Eric Wallace and Asher Macdonald provided research assistance. 
1. Concerns About Unquantifiable Project Benefits and Costs ..................................... 17

2. Concerns About Dynamic Pricing Programs .......... 18

3. Other Concerns............................ 20

E. Energy Law Federalism Poses a Challenge to Federal-State

Cooperation in Building the Smart Grid.............. 20

III. A New Regulatory Framework for the Smart Grid:

Interoperability Standards ....................... 21

A. The Need for Standards and the Foundation of

"Interoperability" ......................... 23

1. Basic Concepts Behind Interoperability Standards...... 24

2. Conceptual Models and "Use Cases" ............. 26

B. How Standards Are Set ........................ 28

1. The Norm: Standard-setting By Private Sector Experts (Standards Development Organizations) ..............

2. An Alternative Form of Standard-setting: Crowdsourcing

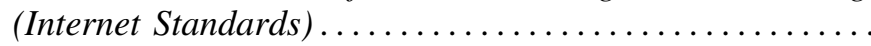

C. Reasons to Depart from the Norm: Federal Standard-setting Involvement for the Smart Grid ................. 32

1. The Smart Grid's Massive Scope and Complexity....... 33

2. Federal Involvement is Necessary to Ensure Grid

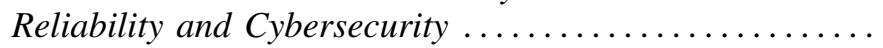

3. Federal Involvement is Necessary to Provide Guidance to States and Overcome Federalism Barriers .............

D. The National Governance Structure Established and in Place for Smart Grid Standards Development...............

1. The NIST-led Process (Smart Grid Interoperability

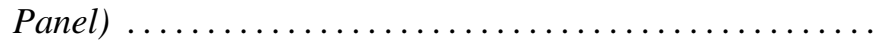

2. The SGIP in Operation: PAP10 (Standard Energy Usage

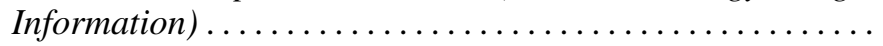

IV. FERC's Order and Its Implications for Smart Grid Development

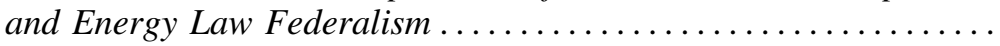

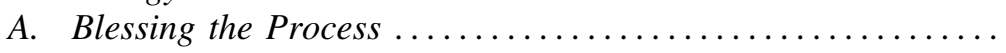

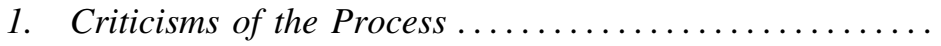

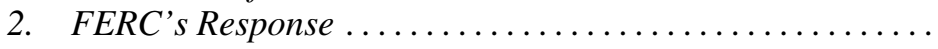

B. Treating Federalism as a Means for Implementation Instead of a Barrier .............................. 50

1. Concerns of Smart Grid Stakeholders ............ 50

2. FERC's Response ....................... 52

C. The Future of Standards — Adoption at the State Level .... 54 Conclusion .................................. 55

\section{INTRODUCTION}

We are at the early stage of creating a Smart Grid, a radically upgraded national electric network that would resemble the Internet in anticipated scale 
and complexity. The efforts to develop a Smart Grid have two different but related objectives: modernizing our electric system's antiquated architecture and providing consumers with dramatic new ways to make, use, and conserve electricity. ${ }^{1}$ The electric grid delivers the product on which modern life depends, ${ }^{2}$ but is the last major network to hold out against fundamental change. ${ }^{3}$ Replacing it with a sophisticated energy ecosystem could enable interactive consumer applications that would yield immense environmental and economic benefits. There would be spectacular technological breakthroughs, the rise of entire new industries, ${ }^{4}$ and consumer uses far beyond anyone's wildest dreams. The Smart Grid could be a strong, secure, multifunctional network ${ }^{5}$ that would be a critical response to climate change, bringing together numerous generation sources and energy-saving technologies into a seamless web.

However, the Smart Grid begins with monopoly utilities in place. This is as if we developed the Internet with just one computer company, instead of the competitive ecosystem of hardware and software providers we have today. That company would have its profit guaranteed by government regulation and therefore little incentive to innovate. ${ }^{6}$ The Smart Grid therefore requires both new technologies and transformative regulatory change. Allowing for the Internet era's mode of disruptive innovation ${ }^{7}$ to bring new services and products to the electric utility industry requires a nimble and open foundation. The

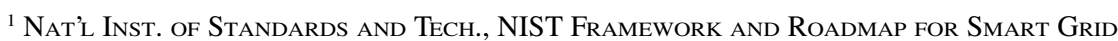
InTEROPERABILITy STANDARDS 23 (Release 1.0 2010) [hereinafter NIST FramewORK 1.0]; Mass. Inst. of Tech., The Future of the Electric Grid 20 (2011). Section 1301 of the Energy Independence and Security Act of 2007 defines the Smart Grid in over ten different objectives that make up a broad collection of ambitious goals. See 42 U.S.C.A. $§ 17381$ (West 2012).

${ }^{2}$ Andres Carvallo \& John Cooper, The Advanced Smart Grid: Edge Power Driving Sustainability 185 (2011) ("Our society has become so dependent on electricity that electricity should be inserted into Maslow's Hierarchy of Needs, at its base.").

${ }^{3}$ Smart Grid Initiatives and Technologies: Hearing Before the Senate Comm. on Energy and Natural Resources, 111th Cong. (2009) (statement of Suedeen Kelly, Commissioner, Federal Energy Regulatory Commission), available at http://www.energy.senate.gov/public/index.cfm/hearings-and-business-meetings?ID=aa1 ce631-aae4-f0e3-0756-d667268c8551 ("Digital technologies have transformed other industries such as telecommunications. A similar change has not yet happened for the electric grid."); Nat'l Sci. and Tech. Council, A Policy Framework For the 21st Century Grid: Enabling Our Secure Energy Future v (2011) ("[T] he traditional electricity infrastructure has changed little from the original design and form of the electric grid as envisioned by Thomas Edison and George Westinghouse at the end of the 19th century.").

${ }^{4}$ See, e.g., Peter Fox-Penner, Smart Power: Climate Change, the Smart Grid, and the Future of Electric Utilities 157-74 (2010) (discussing different business models for the Smart Grid, some of which would radically transform the electric utility industry).

${ }^{5}$ Nat'l Inst. OF Standards and Tech., Draft NIST Framework and Roadmap for Smart Grid InTERoperability Standards 26 (Release 2.0 2011) [hereinafter NIST FrameWORK 2.0].

${ }^{6}$ See generally Joseph P. Tomain, "Steel in the Ground": Greening the Grid with the iUtility, 39 Envtl. L. 931 (2009); see infra notes 76-79 and accompanying text.

${ }^{7}$ Joel B. Eisen, Can Urban Solar Become a "Disruptive" Technology?: The Case for Solar Utilities, 24 Notre Dame J.L. Ethics \& Pub. Pol'y 53, 58-60 (2010); Tim Wu, Network Neutrality, Broadband Discrimination, 2 J. on Telecomm. \& High Tech. L. 141, 145 (2003) (referring to technology and business model innovations that deliver new value to consumers as "a system of belief about innovation, one that has gained significant popularity over [the] last two decades," which Wu terms the "evolutionary model.").
} 
Smart Grid's regulatory base of "interoperability"8 standards must be this foundation. Like Internet protocols, these technical standards will have impacts for decades. ${ }^{9}$ Far from being dry technical documents, they will have profound effects on utilities, suppliers, vehicle and appliance manufacturers, and every consumer of electricity. ${ }^{10}$

Standards, in short, are regulations, ${ }^{11}$ and the development of effective interoperability standards will influence Smart Grid development for years to come. Standard-setting normally involves consensus decisions by industry participants. ${ }^{12}$ However, this Article contends that the Smart Grid requires a federally-coordinated standard-setting process, due to the size of the endeavor, massive coordination difficulties, risk of technology balkanization, and presence of important national interests. With numerous unconnected, proprietary utility systems, and little standardization, ${ }^{13}$ Smart Grid standard-setting is a complex endeavor requiring considerable effort. Without national standards, 51 different state public utility commissions ("PUCs") could adopt 51 different Smart Grid models, or implement systems that fail to protect the grid from cyberattacks. ${ }^{14}$

In the 2007 Energy Independence and Security Act ("EISA"), Congress established a process to set standards in collaborative dialogue among hundreds of participants, with leadership from the National Institute of Standards and

${ }^{8}$ The National Institute of Standards and Technology defines "interoperability" as " $[\mathrm{t}] \mathrm{he}$ capability of two or more networks, systems, devices, applications, or components to exchange and readily use information - securely, effectively, and with little or no inconvenience to the user." NIST Framework 2.0, supra note 5, at 21. See generally GridWise Architecture Council, Interoperability Context-Setting Framework (2007) (discussing different levels and attributes of interoperability); see infra notes 145-55 and accompanying text.

${ }^{9}$ Empowering Consumers and Promoting Innovation through the Smart Grid: Hearing Before the Subcommittee on Technology and Innovation of the Committee on Science, Space, and Technology, 112th Cong. 4 (2011) (statement of George W. Arnold, National Coordinator for Smart Grid Interoperability, National Institute of Standards and Technology) [hereinafter Arnold SS\&T Testimony] ("[T]he foundation we lay with these standards likely will establish the basic architecture of the grid for decades.").

${ }^{10}$ Fed. Energy Regulatory Comm'n, Technical Conference on Smart Grid Interoperability Standards, Opening Remarks by George Arnold, NIST (Jan. 31, 2011), at 4 [hereinafter Opening Remarks to FERC Technical Conference 2011], available at http://www.nist.gov/smartgrid/ upload/technical_conference_013111.pdf; see also generally Fed. Energy Regulatory Comm'n, Technical Conference Smart Grid Interoperability Standard Transcript Document No. RM11-2000 (Jan. 31, 2011) [hereinafter FERC Technical Conference 2011] (containing additional supporting statements by industry participants) (on file with the Harvard Law School Library).

${ }^{11}$ Kevin Werbach, Higher Standards Regulation in the Network Age, 23 HARV. J. L. \& TeCH. 179, 179 (2009).

${ }^{12}$ Arnold SS\&T Testimony, supra note 9, at 8 ("[F]ew, if any, interoperability standards have ever been adopted in regulation for national infrastructures such as the legacy electric grid, the telecommunications system, or the Internet .... In the US, the vast majority of standards are accepted by the market on a purely voluntary basis without any regulatory action or consideration.").

${ }^{13}$ Arnold SS\&T Testimony, supra note 9, at 3 ("The U.S. grid, which is operated by over 3200 electric utilities using equipment and systems from hundreds of suppliers, has historically not had much emphasis on interoperability or standardization.").

${ }^{14}$ See generally U.S. Gov't Accountability Office, GAO-11-117, Electricity Grid Modernization: Progress Being Made on Cybersecurity Guidelines, But Key Challenges Remain to Be Addressed (2011). 
Technology ("NIST"). NIST uses a process to develop standards, which it submits to the Federal Energy Regulatory Commission ("FERC"). FERC then decides whether to adopt the standards as legally binding regulations. ${ }^{15}$ In July 2011, FERC decided, in its Order on Smart Grid Interoperability Standards, ${ }^{16}$ that it would not begin a rulemaking proceeding on the first five standards sent to it. The result was a widespread perception that FERC had put the brakes on the standard-setting process and, therefore, on Smart Grid development as a whole.

This Article argues to the contrary. It concludes that FERC's order supports the flexibility of the NIST process and its creative federally-led crowdsourcing that puts different agents to work to solve the "wicked" problem ${ }^{17}$ of standard-setting in a complex, heavily regulated environment. FERC's order allows the process, not a regulator's imprimatur, to give standards credibility. By holding off on forcing states to adopt the standards, but preserving the potential for more significant federal intervention later, it also embraces an adaptive approach to energy law federalism. This is necessary in the current landscape of jurisdictional clashes between the states and the federal government, because states suggested that a federal takeover of the standards process would provoke conflict and uncertainty. Under the FERC order, states will eventually rely on the standards, even if FERC does not technically mandate them and intervenes only in limited instances. Thus, rather than seeing federalism as a barrier to change, FERC's approach may promote a more positive approach to the federal-state relationship.

Part I discusses the Smart Grid and its revolutionary potential for utilities and consumers. Part II discusses the numerous key barriers to Smart Grid development, including early stage resistance, lack of incentives for consumers, and the adverse impacts of the federal-state tension in energy regulation. Part III discusses the need for interoperability standards, the federally led process to set the standards, and a case study involving standards for energy use information that helped enable a recent "Green Button Initiative," which allows consumers to view their electricity data.

Part IV discusses the FERC order and concludes that it was the proper result for two reasons. First, it validates the Smart Grid Interoperability Panel ("SGIP"), the NIST process that will produce results that will be hailed as foundational to a wide range of energy saving technologies. Second, and perhaps just as importantly, it may lead to state adoption of standards created in a federally-led process. This promotes an approach to energy law federalism in which neither top-down federal regulation nor private-sector standard-setting is the exclusive means of overseeing Smart Grid development. The SGIP process and FERC's response to it are therefore especially noteworthy, because they

1542 U.S.C.A. $\$ 17385$ (d) (West 2012).

${ }^{16}$ FERC, Smart Grid Interoperability Standards, RM11-2-000, 136 FERC II 61,039 (July 19, 2011) [hereinafter FERC Standards Order].

${ }_{17}$ See generally Richard J. Lazarus, Super Wicked Problems and Climate Change: Restraining the Present to Liberate the Future, 94 CORNELl L. REV. 1153 (2009), for a discussion of the literature on "wicked" problems and its application to multifaceted challenges such as this. 
establish a novel approach to defining the federal-state relationship that would avoid the disruptive jurisdictional clashes that have marked recent attempts to innovate in the electric grid.

\section{The Smart Grid's Potential}

As one observer puts it, "[t]hinking about building Smart Grids is similar to saying that we are going to "build the internet." 18 The "Smart Grid" is generally understood as "concepts, technologies, and operating practices intended to bring the electric grid into the 21 st century." 19 This will change the grid "more in the next 10 years than it has in the past 100 years," ${ }^{20}$ but there is little agreement on what that will entail. In 2009, the Department of Energy ("DOE") reported in its first biennial report to Congress that the Smart Grid may transform America as much as the Internet has done, redefining every aspect of electricity generation, distribution, and use. ${ }^{21}$ The EISA describes the Smart Grid as a system capable of accomplishing over ten diverse objectives. ${ }^{22}$ Comprehensive policy frameworks from the federal government and state utility regulators, ${ }^{23}$ Smart Grid alliances, individual utilities and trade associations,${ }^{24}$ and others contain proposals for specific actions and resource decisions.

These visions are so different that they cannot be summarized or reconciled easily. ${ }^{25}$ Compare the electric grid to a reliable 10 -year-old automobile that runs capably and enables its owner to commute each day. Improving electric utility infrastructure is like upgrading the car's systems, or replacing the

${ }^{18}$ A123 Systems, Energy Storage Systems in Emerging Smart Grid Applications (2009), available at http://sdm.mit.edu/conf09/presentations/harvey_wilkinson.pdf. This observation reflects the ease with which so many analogize the Internet's norms and practices to the Smart Grid. The two networks involve similar policy challenges, but the Smart Grid will be different in fundamental ways. For one, the Smart Grid involves revamping an existing network that features extensive commercial use and legalized monopolies. Where analogies prove useful, this Article will employ them, but caution about doing so reflexively is in order.

${ }^{19}$ Lawrence Berkeley Nat'l Lab., Chapters $1-3$, in Smart Grid Technical Advisory Project, An Introduction - Smart Grid 1011 (2011) [hereinafter LBNL Smart Grid 101 CH. 1-3] (on file with the Harvard Law School Library).

${ }^{20}$ Geoff Zeiss, Distributech Utility University: Smart Grid in North America - Progress in Developing Standards, Between The Poles (Jan. 23, 2012), http://geospatial.blogs.com/geospatial/2012/01/distributech-utility-university-smart-grid-in-north-america-and-the-importance-ofstandards.html.

${ }^{21}$ U.S. Dep't of Energy, SMARt Grid System Report (2009), available at http://energy. gov/sites/prod/files/2009\%20Smart\%20Grid\%20System\%20Report.pdf.

${ }^{22}$ See 42 U.S.C.A. § 17381 (West 2012).

${ }^{23}$ See, e.g., NIST Framework 2.0, supra note 5; FERC, Smart Grid Policy, 128 F.E.R.C. II 61,060 (July 16, 2009) [hereinafter FERC Smart Grid Policy]. For a major state policy framework, see N.Y. Pub. Serv. Comm'n, Case 10-E-0285, Smart Grid Policy Statement (2011), available at http://nyssmartgrid.com/wp-content/uploads/2012/09/NYPSC-Smart-Grid-PolicyStatement.pdf.

${ }^{24}$ See , e.g., David Masters, Duke Energy: Developing the communications platform TO ENABLE A MORE INTELLIGENT ELECTRIC GRID (2011), available at http://www.duke-energy.com/ pdfs/OP-David-Masters-SmartGrid-Comm-Platform-02-01-11.pdf.

${ }^{25}$ MAss. Inst. OF TECH., supra note 1, at 20 ("The term "smart grid" has been used to refer to a wide variety of electric grid modernization efforts and ideas over the past several years.”). 
car. The paradigm shift from centralized, one-directional power flow from generation resources through the transmission-distribution system, into two-way dynamic flows, is like selling the reliable car and switching to more complex but more efficient public transit. Consider the implications of this breathtaking statement: "Just as the Internet connected commerce, banking, entertainment, digital media, voicemail systems, and all the other systems that generate or consume information, tomorrow's energy system should connect — or integrate - all of the systems and community assets that will consume or generate electricity." 26

Advanced information and communication systems for this are largely absent. The electric grid "has a tradition of using many proprietary customized systems, and there has never been a need for information systems on the utility side of the meter to interact with systems and devices on the customer side of the meter."27 Yet a Smart Grid means more than "computerizing" the grid. The upheaval we foresee must take place using the spirit of innovation that dominates our time.

The "Smart" in "Smart Grid" should reflect the concept of dynamic innovation that has evolved over the past several decades. Innovation in networks takes place today on open platforms that draw on new energy, ideas, and distributed and meritocratic business practices. Disruptive technologies can produce rapid organizational changes, shifting power within an industry or displacing entire industries almost overnight. ${ }^{28}$ This phenomenon is ubiquitous today, ${ }^{29}$ and we must therefore avoid constraining the grid's Steve Jobs, who would see potential where no one has seen it before. One can imagine a Smart Grid decades from now that is entirely different from anything contemplated today. The term "Internet" (or "Internetting," as it was first called) was coined as the first network technologies were developed, but later evolved into a much different usage and understanding. ${ }^{30}$

A Smart Grid is therefore different from today's grid in two fundamental ways. The first requires adding hardware and software to make the grid more intelligent, in both the utility and consumer domains. The second requires recognition of the spirit of innovation and potential for dynamic competition and new uses.

${ }^{26}$ Pecan St. Proj., Working Group Recommendations 10 (2010).

${ }^{27}$ Opening Remarks to FERC Technical Conference 2011, supra note 10, at 7.

${ }^{28}$ Eisen, supra note 7 , at 58.

${ }^{29} \mathrm{Wu}$, supra note 7 , at 145.

${ }^{30}$ See Leiner et al., Brief History of the Internet, InTERnET Soc'y, http:// www.internetsociety.org/internet/internet-51/history-internet/brief-history-internet (last visited Jan. 23, 2013) (on file with the Harvard Law School Library). 


\section{A. Operational Improvements for a More Efficient Grid}

Some useful short-term benefits will come from intelligent technologies that will provide enhanced information and make the grid more reliable. ${ }^{31} \mathrm{Ma}-$ jor infrastructure companies (in some cases the same ones that upgraded the Internet's switchgear) are making huge bets on the Smart Grid. ${ }^{32}$

At the outset, we are faced with a paradox. The National Academy of Engineering has called the electric grid the most significant engineering achievement of the 20th century, beating out such worthy contenders as the Interstate Highway System and the Internet. ${ }^{33}$ This honor is well deserved. The grid is a "marvel of engineering" and one "of the most interconnected machines on Earth." 34 It works, delivering electricity on a steady, reliable basis. Utilities have spent hundreds of millions of dollars to update the grid with intelligence for their transmission and distribution systems. Peer into a modern control operator's "cockpit," and marvel at its human maestros' deftness in balancing the electricity system in real time. ${ }^{35}$

Yet this is not the same as a Smart Grid. For one, intelligence is not present everywhere on the network. Many locations lack sensors and other technologies that would allow system operators to understand how much electricity is flowing or what else is happening. ${ }^{36}$ Some, but not all, utilities have Supervisory Control and Data Acquisition ("SCADA") systems that monitor grid components and communicate from the field about potential disaster situations. ${ }^{37} \mathrm{~A}$ utility often only knows where an outage is located when it receives a customer's phone call.

Advanced systems are often "siloed," not interconnected. ${ }^{38}$ SCADA systems use proprietary technology tailored to specific networks, which frequently

${ }^{31}$ Learn More about Smart Grid, Smart Grid Information Clearinghouse, http:// www.sgiclearinghouse.org/LearnMore (last visited Jan. 22, 2013) (on file with the Harvard Law School Library) ("Much in the way that a 'smart' phone these days means a phone with a computer in it, smart grid means 'computerizing' the electric utility grid.").

${ }^{32}$ See U.S. Gov't Accountability OfFICE, supra note 14 , at 32-34.

${ }^{33}$ Nat'l Sci. and Tech. Council, A Policy Framework for the 21st Century Grid: Enabling Our Secure Energy Future 1 (2011), available at http://www.whitehouse.gov/sites/ default/files/microsites/ostp/nstc-smart-grid-june2011.pdf.

${ }^{34}$ NOVA: Smart Grid, (PBS television broadcast Feb. 23, 2011), transcript available at http:// www.pbs.org/wgbh/nova/tech/power-grid.html.

${ }_{35}$ The difficult duties of system operators are described in Matthew L. Wald, On the Front Lines of the Power Grid, N.Y. TIMES, Oct. 25, 2011, http://www.nytimes.com/2011/10/26/business/energy-environment/behind-the-power-grid-humans-with-high-stakes-jobs.html?pagewanted $=$ all\&_r $=0$.

${ }^{36}$ See U.S. Gov't AcCountability OfFICE, supra note 14, at 4-5.

${ }^{37}$ Nat'l Commc'n Sys., Technical Information Bulletin 04-1, Supervisory Control and Data Acquisition (SCADA) Systems 4 (2004), available at http://www.ncs.gov/library/ tech_bulletins/2004/tib_04-1.pdf ("SCADA systems are used to monitor and control a plant or equipment in industries such as telecommunications, water and waste control, energy, oil and gas refining and transportation. These systems encompass the transfer of data between a SCADA central host computer and a number of Remote Terminal Units (RTUs) and/or Programmable Logic Controllers (PLCs), and the central host and the operator terminals.").

${ }^{38}$ The "walled silo" metaphor is often used to describe utility systems. Ali Ipakchi \& Farrokh Albuyeh, Grid of the Future: Are We Ready to Transition to a Smart Grid?, IEEE PowER \& 
does not connect with other utilities' systems. ${ }^{39}$ One utility might use a thirdgeneration networked SCADA system built on standard communications protocols ${ }^{40}$ and another might have a simpler, older system. Proprietary systems present a major problem in the Smart Grid, which requires careful consideration of how to link billions of dollars worth of legacy equipment into an advanced communications network.

Digital technologies can improve the grid's reliability, security, and efficiency. This will involve deploying sensors and other intelligent components to provide system operators with more detailed data. High-tech synchrophasors (devices that measure conditions on transmission lines more effectively) ${ }^{41}$ and expert communication systems would give system operators greater ability to observe the grid's overall condition (known as "wide-area situational awareness"). They could automatically balance power flows, report outages, and receive weather, demand, and performance data nearly in real time. ${ }^{42}$

This advanced intelligence also allows generation to be added and distributed throughout the grid. ${ }^{43}$ Adding distributed generation ("DG") resources to the grid will diversify supply, reduce risks of major outages, and improve overall grid reliability. ${ }^{44}$ This would also encourage the use of renewable energy generation sources (such as solar) which is an important response to climate change. A more supportive environment for DG would require communications protocols, data models, and intelligent controls that are still not yet well understood. ${ }^{45}$ Researchers are working on ways to enable more widespread DG

ENERGY, Mar. 2009, at 12 ("In most cases, the information in each organizational 'silo' is not easily accessible to applications and users in other functional units.”); Arnold SS\&T Testimony, supra note 9 (The electric utility industry has "many proprietary interfaces and technologies that result in the equivalents of stand-alone silos.").

${ }^{39}$ Nat'L CommC'N SYs., supra note 37 , at 8.

${ }^{40} \mathrm{Id}$. at 15 . A common standard is the IEC $60870-5$ series, which, in its upgraded "6" version, was also one of first five families of Smart Grid standards submitted by NIST to FERC. George W. Arnold, Smart Grid Standards Ready for Consideration by Regulators 2 (2010), available at http://www.ferc.gov/EventCalendar/Files/20101119155511-Arnold, \%20NIST.pdf.

${ }^{41}$ Matthew L. Wald, For the Smart Grid, a 'Synchrophasor', N.Y. Times GreEN Blog (Apr. 1, 2010), http://green.blogs.nytimes.com/2010/04/01/for-the-smart-grid-a-synchophasor/.

${ }^{42}$ See Lisa Schwartz, Regulatory Assistance Proj., Smart Policies Before Smart Grids: How State Regulators Can Steer Investments Toward Customer-Side Solutions 7 (2010). One report notes the proliferation of large data centers throughout the nation, and suggests using them to handle and manage the flow of information. Nat'L Elec. Mfrs. Ass'N, Standardizing the Classification of Intelligence Levels and Performance of Electricity Supply Chains 16 (2009).

${ }^{43}$ LBNL SMART GRID $101 \mathrm{CH}$. 1-3, supra note 19 , at 8 (discussing the potential for adding generation "at bulk power transfer points, substations, other distribution locations and on the customer side of the meter.").

${ }^{44}$ Lesley K. McAllister, Adaptive Mitigation in the Electric Power Sector, 2011 B.Y.U. L. REV. 2115, 2137 (2011).

${ }^{45}$ NAt'L Elec. Mrrs. Ass'N, supra note 42, at 13 (noting that "the integration of DG sources into a utility's operation environment is still an active research field"); LAWRENCE BERKELEY Nat'l Lab., Use of Frequency Response Metrics to Assess the Planning and Operating Requirements for Reliable Integration of VARiable Renewable Generation (2010), available at http://www.ferc.gov/industries/electric/indus-act/reliability/frequencyresponsemetrics-report.pdf (discussing challenges of frequency regulation on the grid when integrating DG) [hereinafter Lawrence Berkeley Nat'L Lab. Frequency Report]. 
integration, and more effective functioning of the grid under real-time conditions. ${ }^{46}$ This is one way in which a Smart Grid entails more than simply upgrading a piece of hardware.

\section{B. Disruptive Consumer Applications}

The Smart Grid's potential for consumers is enormous. At present, a typical customer's interaction with a utility is limited to a wire into the house, a monthly bill, and maintenance trucks that roll in during storms. Like the dashboard of an early 20th-century automobile, a typical utility meter today has rudimentary instrumentation and only measures electricity usage. ${ }^{47}$ Customers receive monthly bills, often still on paper. Utility websites may not allow customers to see their usage data. Data presented are typically monthly usage totals, with little to no information on how much electricity individual appliances consume, or how consumers might alter their behavior to save energy and money.

The Smart Grid promises to dramatically change the relationship between utilities and their customers, starting with advanced communication systems. "Advanced metering infrastructure," better known as "smart meter" technology, is the Smart Grid component most visible to consumers. ${ }^{48}$ By 2015, 65 million American homes and businesses may have smart meters that enable two-way communication between utilities and customers. ${ }^{49}$ Smart meters allow customers to view their real-time electricity use. This has potential benefits for utilities, which, for example, can manage outages more efficiently, and connect new customers to the grid without sending trucks to their locations. ${ }^{50}$

Having near real-time information about energy usage can show consumers how to reduce consumption. ${ }^{51}$ A smart meter could also show the real-time price of electricity, ${ }^{52}$ and help consumers save money. Demand for electricity peaks at various times during the typical day. Using a smart meter, a consumer could time shift and lower her electricity usage when demand and prices are

${ }^{46}$ Lawrence Berkeley Nat'l Lab. Frequency Report, supra note 45.

${ }^{47}$ Mass. Inst. OF TeCH, supra note 1, at 132-33.

${ }^{48}$ See LBNL Smart Grid 101 CH. 1-3, supra note 19, at 11, 17.

${ }^{49}$ Inst. for Elec. Efficiency, Utility-Scale Smart Meter Deployments, Plans, \& ProPOSALS 1 (2012), available at http://www.edisonfoundation.net/iee/Documents/IEE_SmartMeter Rollouts_0512.pdf.

${ }^{50}$ Inst. for Elec. Efficiency, The Costs and Benefits of Smart Meters for ResidenTIAL Customers 3 (2011), available at http://www.smartgridnews.com/artman/uploads/1/IEE_ Benefits_of_Smart_Meters_Final.pdf ("utility operational advantages such as outage detection and management, remote meter reading, and remote customer (dis)connections"). In the aftermath of Hurricane Sandy's widespread power outages in the Northeast in 2012, some observers noted that smart meters and other Smart Grid technologies cut the time necessary to bring power back after major storms. See Martin LaMonica, Smart Meters Help Utility Speed Sandy Restoration, MIT TEch. REv., Oct. 31, 2012, available at http://www.technologyreview.com/view/ 506711/smart-meters-help-utility-speed-sandy-restoration/.

${ }^{51}$ Schwartz, supra note 42 , at 6.

${ }^{52}$ Id. 
high. ${ }^{53}$ As space age as it sounds, a properly-equipped washing machine could be programmed to run at lower-cost times, or the consumer could even allow the utility to control it, in return for financial incentives. Little of this is in place today, but manufacturers are scrambling to deliver advanced products to market. ${ }^{54}$

A smart meter can also make lower-cost charging of plug-in electric vehicles ("PEV") possible by charging cars during off-peak periods. Together with a management system, a smart meter can also link with battery technology (including the batteries in PEVs and hybrid-electric vehicles) to store electricity generated when it is inexpensive to produce. Storage is a potential game changer for the Smart Grid, if it allows consumers to buy electricity at inexpensive times and use it later. ${ }^{55}$

Advanced communications systems can also expand consumers' "demand response" ("DR") ${ }^{56}$ opportunities. Demand response includes consumers' voluntary reductions in demand through programs that reward lower electricity use, and load control, by allowing a utility or authorized third party to control devices directly (for example, by shutting or cycling off a device such as an air conditioning unit in response to high demand on the system). ${ }^{57}$ Direct load control is increasingly becoming a valuable commodity of its own in wholesale electricity markets. ${ }^{58}$ Consumers could capture that value when a smart meter measures the reduction in demand, which today's load control equipment typically cannot do. ${ }^{59}$

${ }^{53}$ Michael P. Vandenbergh \& Jim Rossi, Good for You, Bad for Us: The Financial Disincentive for Net Demand Reduction, 65 VAND. L. REv. 1527, 1540 (2012) ("Smart meter programs also reflect the focus of DSM on shifting electricity use from peak to off-peak hours").

${ }^{54}$ See, e.g., Green Biz Staff, Whirlpool Set to Launch Smart Grid Compatible, GreEN BIz BLOG (May 8, 2009), http://www.greenbiz.com/news/2009/05/08/whirlpool-set-launch-smartgrid-compatible-appliances-2015; Katie Fehrenbacher, 10 Ways Big Data is Remaking Energy, GigAom (Jan. 29, 2012), http://gigaom.com/cleantech/10-ways-big-data-is-remaking-energy/ ("One of the biggest trends from DistribuTECH this year was the overwhelming amount of smart thermostats that are now being sold and marketed.").

${ }^{55}$ Edward H. Comer, The Future of Energy Law-Electricity, 31 Utah EnvTL. L. Rev. 429, 430 (2011) (president of utility trade association Edison Electric Institute noting that "the ability to store electricity efficiently and cheaply can truly change the economics, and potentially the structure, of the industry"); see also A123 Systems, supra note 18; James Greenberger, The Curious Disconnect Between Smart Grid and Energy Storage, The Energy Collective (Oct. 27, 2011), available at http://theenergycollective.com/jim-greenberger/67538/curious-disconnect-between-smart-grid-and-energy-storage.

${ }^{56}$ NAt'L Elec. Mfrs. Ass'N, supra note 42, at 13 ("Demand response (DR) is the adjustment of consumer demand in response to real-time system operating conditions."). See also generally Joel B. Eisen, Who Regulates The Smart Grid?: FERC's Authority Over Demand Response Compensation in Wholesale Electricity Markets, San Diego J. of Climate and Energy L. (forthcoming 2013) (on file with Harvard Law School Library).

${ }^{57}$ SchwARTz, supra note 42 , at 6 . The author has taken part in a pilot program by the utility Dominion Virginia Power involving direct load control of air conditioning units. See Former Conservation Initiatives, DominIon, http://www.dom.com/dominion-virginia-power/customer-service/energy-conservation/pilot-programs.jsp (last visited Jan. 22, 2013) (on file with the Harvard Law School Library).

${ }^{58}$ InST. FOR ELEC. EFFICIENCY, supra note 49, at 10.

${ }^{59}$ InSt. FOR ELEC. EFFICIENCY, supra note 50, at 9 (noting that "load control equipment in use today generally cannot measure and verify usage during a load control event"). 
DR can be important to a utility as part of its overall strategy to meet future anticipated demand and avoid unnecessary expenses of building new generation, transmission, and distribution infrastructure. ${ }^{60}$ Yet while utilities have offered DR programs for decades, they have underinvested in them. The utility is in effect "anti-selling" its product, and state regulation traditionally rewards utilities for increased sales. State PUCs are only recently embracing "decoupling" incentives that reward utilities for promoting DR. ${ }^{61}$

The challenge of promoting DR will look like an opportunity to many firms. ${ }^{62}$ Third parties could compete with utilities by providing energy information and management services to consumers. ${ }^{63}$ Over time, firms that analyze customer data (data analytics firms, for example) may become adept at parsing through the massive data smart meters generate. ${ }^{64}$ Some are already hard at work trying to turn data into customer empowerment. ${ }^{65}$ Eventually, these firms might even purchase power at wholesale and supply their customers, as some firms are already doing with commercial buildings. Another possibility is that entire buildings or "micro-grids" might go off the electric grid altogether, using intelligent technologies to create local networks for distribution of electricity generated locally. ${ }^{66}$

${ }^{60}$ See generally Paul Pietsch, Ass'n for Demand Response and Smart Grid, Demand Response \& Smart Grid - State Legislative and Regulatory Policy Action Review: MAY 2010 - JUNE 2011 (2011), available at http://sgstage.nrel.gov/sites/default/files/doc/files/ 4512_doc_1.pdf (describing DR programs in the states).

${ }^{61}$ Brown, Levitsky, \& Salter, Smart Grid and Competition: A Policy Paper 94 (2011) ("[I]n the case of most states where rates are not decoupled, a considerable part of the value of the new meters, namely energy saving, reduces utility revenue and, therefore, is contrary to their interest, so there is a real risk that the new devices will be underutilized with utilities in control."); Vandenbergh \& Rossi, supra note 53, at 1534 (discussing this and other disincentives for DR and observing that "widespread demand reduction is not likely to occur until utilities shift from viewing efficiency and conservation as revenue erosion to a financial opportunity").

${ }^{62} 2011$ State of the Consumer Report, SMart Grid Consumer Collaborative, at 4 (Jan. 31, 2011), available at http://www.pointview.com/data/files/4/3696/1942.pdf ("Building on decades of commercial and industrial demand response, direct load control, and energy efficiency programs for consumers, the utility sector is on the cusp of a similar, disruptive transformation.").

${ }^{63}$ Richard Tabors, Why Today's Utilities May Soon Be Obsolete (and What May Replace Them), SMARTGridNews.COM (Jan. 27, 2010), http://www.smartgridnews.com/artman/publish/ Business_Markets_Pricing_News/Why-Today-s-Utilities-May-Soon-Be-Obsolete-and-What-MayReplace-Them-1782.html.

${ }^{64}$ Elias L. Quinn \& Adam L. Reed, Envisioning the Smart Grid: Network Architecture, Information Control, and the Public Policy Balancing Act, 81 U. Colo. L. Rev. 833, 882 (2010); see also Steve Lohr, The Age of Big Data, N.Y. Times, Feb. 11, 2012, http://www.nytimes.com/2012/ 02/12/sunday-review/big-datas-impact-in-the-world.html?pagewanted $=$ all\&_r $=0$ (arguing that a societal "explosion of data" creates new opportunities for "data-driven discovery and decisionmaking").

${ }^{65}$ Katie Fehrenbacher, supra note 54 (discussing the job of startups like OPower and Tendril) ("Essentially these companies have collected data on consumers and demographics and they are using it to try to guess the best way to influence the consumer to do things like upgrade their home appliances and lights to more efficient ones.").

${ }^{66}$ Elec. Power Research Inst., Needed: A Grid Operating System To Facilitate Grid TRANSFORMATION 6 (2011) [hereinafter EPRI GRID 3.0] (“[E]nergy sources and a power distribution infrastructure can be integrated at the local level. This could be an industrial facility, a commercial building, a campus of buildings, or a residential neighborhood."). See generally Sara C. Bronin, Curbing Energy Sprawl With Microgrids, 43 ConN. L. REv. 547 (2010) for a description of some challenges involved. 
Sophisticated energy management systems can empower consumers, but simplicity will be a key variable. ${ }^{67}$ Studies show that some homeowners react favorably to the prospect of saving on their electric bills. ${ }^{68}$ Yet if an energy management system is not "set it and forget it," demand for it may be ephemeral.

The literature on disruptive innovation suggests strongly that third parties are more likely than utilities to succeed with consumers. ${ }^{69}$ As these do not yet exist, we cannot be sure what product or business model will become dominant. Utilities might morph into powerhouse "iUtilities"70 to provide new energy services, but it may be too much to ask them to reverse their focus on supplying electricity and somehow develop an Apple-like responsiveness to consumers' needs. ${ }^{71}$ They understand technology upgrades that improve their operations and their bottom line, but they have never sold devices such as washing machines $^{72}$ or priced, marketed, or sold consumer products.

Therefore, we can and should expect that entrepreneurs will eventually make more effective use of the Smart Grid than utilities. Software companies working with data, like a certain company that started with a better way to search the Internet, might be the ultimate Smart Grid winners. ${ }^{73}$

\section{Key Barriers to Smart Grid Development}

As dazzling as the future appears, the pace of progress is not likely to be quick in the near-term, due to a number of barriers to more rapid development of the Smart Grid. These include the inherent conservatism of utilities and state PUCs that adopt utilities' Smart Grid proposals, an existing regulatory system

\footnotetext{
${ }^{67}$ Smart Grid Consumer Collaborative, supra note 62, at 5 ("[O]ptions and interfaces must evolve to meet the needs of less technically-oriented consumers.").

${ }^{68}$ See Ahmad Faruqui, Ryan Hledik \& Sanem Sergici, The Brattle Group, Piloting the Smart Grid 8-13 (June 2009) (manuscript), available at http://ssrn.com/abstract=1414387 (describing customer participation in pilot programs); SMART Grid Consumer Collaborative, supra note 62 , at 16 .

${ }^{69}$ Richard Tabors, supra note 63 ("In all likelihood, the actual form that the Smart Market takes will not fit neatly into one of these models. Rather, there will be mixing and matching as business strategies are rolled out and the results come back from early pilots.").

${ }^{70}$ Tomain, Steel in the Ground, supra note 6; Joseph P. Tomain, Ending DirTy Energy Policy: Prelude to Climate Change 171-74 (2011) (discussing new products and services that an "iUtility" could offer).

${ }^{71}$ Quinn \& Reed, supra note 64, at 879 (noting that "there is no reason to think that utilities would be especially skilled in developing analysis and behavior modification applications, given their traditional supply-side concerns").

${ }^{72}$ Lawrence Berkeley Nat'l Lab., Chapter 7, in Smart Grid Technical Advisory ProJect, An Introduction - SMARt Grid 1014 (2011) [hereinafter LBNL SMART Grid $101 \mathrm{CH}_{\text {. }}$ 7] (on file with the Harvard Law School Library) ("While Utilities can provide customers with an air conditioner control switch, they cannot provide customers with the diversified range of appliances and electronic devices that populate their premises and business which have capability and are necessary to provide smart grid benefits.").

${ }^{73}$ H. Russell Frisby, Jr. \& Jonathan P. Trotta, The Smart Grid: The Complexities and Importance of Data Privacy and Security, 19 Commlaw Conspectus 297, 298 (2011) (claiming that "in our Smart Grid future, companies such as Google may play as important a role in providing energy services as traditional electric utilities do today.”).
} 
that does not adequately encourage Smart Grid investments, ${ }^{74}$ consumer unfamiliarity with the Smart Grid (and, in some cases, resistance to it), concerns with protecting privacy of data generated by smart meters, and a federalism tension between the FERC and state PUCs that threatens to hamper governments' abilities to cooperate in Smart Grid development. ${ }^{75}$ Each of these barriers needs to be addressed, or the result, like everything in the utility industry, is likely to be exceedingly slow change.

\section{A. Utilities Lack Incentives to Innovate}

For years to come, progress in building out a Smart Grid will depend on actors (utilities) whose conservatism has retarded innovation. Under cost of service regulation, a utility has little incentive for taking risks. Utilities have to supply enough electricity to meet demand at all times. State regulation avoids risks to ratepayers and protects service and reliability. ${ }^{76}$ It does not offer incentives for utilities to invest in innovative new technologies. ${ }^{77}$ For example, it provides a disincentive to investing in equipment whose cost cannot be recovered over a long time horizon, unless the cost can be fully recovered from consumers. ${ }^{78}$

Although utilities have different time horizons, many plan decades ahead, and they want to know products are proven and will stand the test of time before they deploy them. ${ }^{79}$ The regulatory process itself takes time, and leads to slow change. Smart innovation, with its dynamism and the ability to learn from failures, is not the norm. The result is stasis. Large utilities are like fourteenth-century Italian city-states: powerful, independent, and content with the status quo. Changing this system will take time.

\footnotetext{
${ }^{74}$ Charles M. Davidson \& Michael J. Santorelli, Realizing the Smart Grid Imperative: A Framework for Enhancing Collaboration Between Energy Utilities and Broadband Service Providers, 9 (Summer 2011) ("[T]here appears to be an inevitable tension between how various stakeholders, including those in the energy sector, want the smart grid to develop and the existing regulatory structure that will ultimately guide its deployment.").

${ }^{75}$ See e.g., Ashley C. Brown, Controversies and Sources of Resistance to Smart GRID DePloYMEnt (2010), available at http://www.hks.harvard.edu/hepg/Papers/2010/Ashley_ BrownHEPGSept2010.pdf; Paula M. Carmody, Smarting from Resistance to the Smart Grid (Presentation to the Harvard Energy Policy Group) (Sep. 29, 2010), available at http://www.hks. harvard.edu/hepg/Papers/2010/Paula_Carmody_HEPGSept2010.pdf.

${ }^{76}$ Davidson \& Santorelli, supra note 74 , at $9,18$.

${ }^{77}$ Quinn \& Reed, supra note 64, at 860 (noting the "now-familiar economic disincentives to investing in technologies that inhibit utility profitability").

${ }^{78}$ BROWN ET AL., supra note 61, at 97.

${ }^{79}$ Kevin Dasso, The Three Most Common Misconceptions about Smart Grid, ENTREPRENEURSHIP REv. (Dec. 20, 2010), available at http://miter.mit.edu/article3-most-common-misconceptions-about-smart-grid-utility-perspective-kevin-dasso-sr-director-sm/ ("[U]tilities have notoriously high standards for proven product performance before they are willing to invest. . . Therefore, utilities will wait for convincing demonstrations of reliability before investing, beyond demonstrations of mere technological capability[.]"); Matthew Lynley, Why Won't Utility Companies Innovate? Smart Grid Leaders Explain, VentureBeat (Nov. 4, 2010), http://venturebeat. com/2010/11/04/why-wont-utility-companies-innovate-smart-grid-leaders-explain/ ("[U]tility providers are often the slowest to innovate because of both reliability and cost issues[.]").
} 


\section{B. Consumers Know Little About the Smart Grid and Face High Transaction Costs in Translating Interest Into Action}

Consumer demand for the Smart Grid is lacking, as there are inadequate incentives for consumers to adopt systems to manage their electricity consumption. Today's Smart Grid products are not appealing to consumers. No one is standing in line at an Apple Store for a smart thermostat. ${ }^{80}$ These products are "utilitarian" and do not "command the emotional connection we have with smart phones or tablets." 81 Also, consumers may not be interested in "demand response" because it involves using less electricity. Many consumers may not see the potential benefits of this, ${ }^{82}$ because they typically have little to no realtime information about the price of electricity. ${ }^{83}$ Utilities make inadequate attempts to educate their customers about the Smart Grid. Consequently, most consumers know little about it, and there is an "attitude-behavior gap": Those who view benefits most favorably are not inclined to purchase energy management systems. ${ }^{84}$

Another major problem with Smart Grid consumer applications is that even motivated consumers face high transaction costs simply to get started. To assess whether an energy management system might save electricity, a consumer needs fine-grained information about current baseline usage. Most current meters do not generate such data, but smart meters do. An open and important question that has yet to be comprehensively addressed is whether consumers would even have access to this fine-grained usage data. There are ongoing disputes about whether a customer or her utility owns the data a smart meter generates. Without a resolution of this problem, many Smart Grid benefits will be hard to come by.

${ }^{80}$ See Smart Grid Consumer Collaborative, supra note 62, at 26-28.

${ }^{81}$ Eric Wesoff, Nest Labs' Thermostat: Sexy? Yes. Functional? Maybe Not., GreenTech MEDIA (Jan. 18, 2012), http://www.greentechmedia.com/articles/read/Nest-Labs-Thermostat-SexyYes.-Functional-Maybe/ (discussing the drawbacks of the Nest smart thermostat).

${ }^{82}$ Vandenbergh \& Rossi, supra note 53, at 1529 (noting that the "magnitude of the [DR] opportunity is subject to debate").

${ }^{83} \mathrm{Id}$. at 1541.

${ }^{84}$ Smart Grid Consumer Collaborative, supra note 62, at 26 (noting that "those who are most motivated by cost savings on their bill are not necessarily the ones willing to pay more for a home energy management system that will allow them to achieve their goals").

An intriguing development that might address this problem is the marriage of social media and energy efficiency in an app that allows users to post energy usage statistics and claim bragging rights over their friends. Leslie Meredith, New Facebook App the 'Farmville' of Energy Conservation?, Foxnews.com (Oct. 21, 2011), http://www.foxnews.com/scitech/2011/10/21/newfacebook-app-highlights-energy-conservation/; see also William Pentland, Can Smart Apps Save the Smart Grid?, Forbes.COM (Oct. 18, 2011), http://www.forbes.com/sites/williampentland/ 2011/10/18/can-smart-apps-save-the-smart-grid/ "“iPhone sales only started to really explode after the apps market came online,' said Segall. 'Smart Apps can do the same thing for utilities, customers and the smart grid." ").

As Michael Vandenbergh and Jim Rossi point out, utilities have been slow to embrace social media. Vandenbergh \& Rossi, supra note 53, at 1548 n.71; see also Carolyn Elefant, The "Power" of Social Media: Legal Issues \& Best Practice For Utilities Engaging Social Media, 32 ENERGY L.J. 1, 1 (2011) (noting that utilities were once "Web 2.0 luddites" but are now increasingly experimenting with social media). 


\section{Privacy Concerns Present As-Yet Unresolved Challenges}

When large quantities of data are potentially transmitted over a network, we also confront substantial privacy implications. The voluminous literature on Internet privacy shows how modern network technologies present an ongoing threat to personal autonomy. ${ }^{85}$ Similarly, smart meters, devices, and systems may generate reams of data never before available. Utilities are not accustomed to the challenges of real-time communication over a network. ${ }^{86}$ They have not analyzed massive amounts of consumer data and do not understand the sophisticated techniques that third parties use to share data on the Internet without individuals' knowledge or consent. ${ }^{87}$

Some recent articles have begun to grapple with the complexities involved in protecting consumer privacy. ${ }^{88}$ One commentator, for example, explores the difficulties of addressing privacy concerns when third parties enter the energy services business. ${ }^{89}$ The prospect of meshing social networking and energy usage reduction adds the familiar challenges of maintaining privacy in social media. ${ }^{90}$ If you can be fired because a friend posted racy pictures on your Facebook page, we have to wonder what could happen if a friend identified your air conditioner as an energy hog.

An additional privacy concern is that smart meters yield information that could identify environmental behavioral patterns that regulators might want to limit. There is an extensive body of literature on the potential link between environmental law (particularly addressing climate change) and individual behavior. ${ }^{91}$ In the Smart Grid, we find ourselves on the frontier of balancing environmental gains and our need for eco-privacy. Regulators might be tempted to use Smart Grid data to achieve environmental goals, at the expense of consumer privacy..$^{92}$

${ }^{85}$ See generally A. Michael Froomkin, The Death of Privacy?, 52 Stan. L. Rev. 1461 (2000); Lori Andrews, I Know Who You Are and I Saw What You Did: Social Networks and the Death of Privacy (2012).

${ }^{86}$ BROwn ET AL., supra note 61 , at 94.

${ }^{87}$ See generally ANDREWs, supra note 85.

${ }^{88}$ See, e.g., Sonia McNeil, Privacy and the Modern Grid, 25 Harv. J. of L. \& Tech. 199 (2011); Frisby, Jr. \& Trotta, supra note 73; Cheryl Dancey Balough, Privacy Implications of Smart Meters, 86 ChI.-Kent L. Rev. 161 (2011); Stephanie M. Stern, Smart-Grid and the Psychology of Environmental Behavior Change, 86 CHI.-KENT L. REv. 139 (2011).

${ }^{89}$ Andreas S.V. Wokutch, The Role of Non-Utility Service Providers in Smart Grid Development: Should They Be Regulated, and If So, Who Can Regulate Them?, 9 J. on Telecomm. \& High TeCH. L. 531 (2011).

${ }^{90}$ ANDREws, supra note 85 , at 4-5.

${ }^{91}$ See, e.g., Thomas Dietz et al., Household Actions Can Provide a Behavioral Wedge to Rapidly Reduce U.S. Carbon Emissions, 106 Proc. NAT'L. Acad. ScI. 18,452 (2009); Michael P. Vandenbergh \& Anne C. Steinemann, The Carbon-Neutral Individual, 82 N.Y.U. L. Rev. 1673 (2007); Michael P. Vandenbergh et al., Implementing the Behavioral Wedge: Designing and Adopting Effective Carbon Emissions Reduction Programs, 40 EnvTl. L. ReP. 10,547 (2010).

92 This theme is explored in Katrina Fischer Kuh, Personal Environmental Information: The Promise and Perils of the Emerging Capacity to Identify Individual Environmental Harms, 65 VAND. L. REV. 1565 (2012). 
This and other important privacy issues must be addressed now. At present, efforts to address privacy issues are ad hoc, as concerned citizens and advocacy groups bring them to the attention of state PUCs, some of which have taken steps to address the relevant issues. ${ }^{93}$ Without a more systematic approach, the entire Smart Grid effort might be derailed before it gets off the ground. ${ }^{94}$

\section{State PUCs Have Resisted Approving Smart Grid Projects}

State PUCs have authority to regulate retail sales of electricity by distribution utilities, ${ }^{95}$ and evaluate Smart Grid project proposals subject to their jurisdiction on an individual basis. This often includes decisions whether to allow utilities to recover Smart Grid project costs from customers, ${ }^{96}$ using the familiar tools of economic regulation to estimate project benefits and costs. Across the nation, utilities have had some successes with Smart Grid projects, but other projects have encountered resistance from PUCs.

\section{Concerns About Unquantifiable Project Benefits and Costs}

The first concern for many PUCs is an asymmetry about market risk. The value of project benefits is hard to assess, and different in each utility's system. ${ }^{97}$ There is no data from successful projects yet, and PUCs must predict the future. PUCs have been skeptical where utilities pitch the value of operational improvements, thinking consumers may not benefit. ${ }^{98}$ In an early case, the Maryland PSC rejected a "tracker" mechanism to allow Baltimore Gas and Elec-

${ }^{93}$ See Decision Adopting Rules to Protect the Privacy and Security of Electricity Usage Data, CAl. Pub. Util. Comm'n (July 29, 2011), available at https://www.cdt.org/files/pdfs/PUC\%20 Smart\%20Grid\%20Final.pdf.

${ }^{94}$ Quinn \& Reed, supra note 64, at 874-75; see also McNeil, supra note 88, at 25-31 (calling for federal legislation to address Smart Grid privacy issues).

${ }^{95}$ See Regulatory Assistance Proj., Electricity Regulation in the US: A Guide 11 (2011), available at http://www.raponline.org/document/download/id/645 [hereinafter REGULAtory Assistance Proj. Regulation Guide].

${ }^{96}$ See id. at 36-37 (discussing costs recoverable by utilities). FERC regulates wholesale electricity sales and transmission of electricity in interstate commerce. Id. at 11 . It therefore has authority to allow utilities to recover the costs of investments they make to the transmission system, and FERC's Smart Grid Policy set conditions for utilities to recover Smart Grid-related investments there. FERC Smart Grid Policy, supra note 23.

${ }^{97}$ N.Y. Pub. Serv. Comm'N, supra note 23, at 32 (“[A]bsent pilot projects or other field studies, actual benefits are difficult to reliably predict."); see also Elec. Power ReSEARCh Inst., Methodological Approach for Estimating the Benefits and Costs of Smart Grid DemOnStRation Projects 2-16 to 2-23 (2010) (defining a comprehensive approach to estimating benefits).

${ }^{98}$ See Petition of Massachusetts Electric Company and Nantucket Electric Company National Grid, each d/b/a National Grid for Approval of a Smart Grid Pilot Program, Order No. 09-32, Mass. Dep't of Pub. Util. X-xi, 35-36, 41 (2010), available at http://www.env.state.ma.us/dpu/ docs/electric/09-32/72710dpuord.pdf. 
tric Company ("BGE") to begin recovering its investment while it was deploying over one million smart meters. ${ }^{99}$

Near-term Smart Grid approvals will be tentative, due in large part to a chicken and egg problem. We will not know the value of project benefits until we move forward, but we won't move forward without knowing we will benefit. In addition, we cannot risk compromising reliability. Like an airplane flying at 30,000 feet, we can't "stop" the grid, 100 but we have to try new ideas to learn what works. This makes R\&D projects, ${ }^{101}$ pilot projects and phased rollouts of smart meters an essential near-term strategy. It is better to let people test drive cars than force them to give up reliable 10-year-old vehicles.

Funding in the American Recovery and Reinvestment Act of 2009 ("ARRA" or the "stimulus bill") ${ }^{102}$ supported numerous Smart Grid pilot projects. Federal funds defraying half the cost made projects look more appealing to PUCs, and the stimulus bill had the desired stimulating effect, supporting deployment of 18 million smart meters. ${ }^{103}$ There is considerable variety and experimentation in these early projects. ${ }^{104}$ ARRA funding also prompted calls for rapid development of interoperability standards, which put pressure on that process to move quickly.

\section{Concerns About Dynamic Pricing Programs}

Another reason for PUC reluctance to approve many projects is that consumer benefits of smart meter deployment are said to depend on "dynamic"

${ }^{99}$ Application of Baltimore Gas \& Electric Company for Authorization to Deploy a Smart Grid Initiative and to Establish a Surcharge for the Recovery of Cost, Order No. 83410, MD. PuB. UTIL. COMM'N 3 (2010).

${ }^{100}$ EPRI GRID 3.0, supra note 66, at 16 (fundamental change to the grid is "like replacing an engine on a jet plane while it is flying at 30,000 feet. Much like the plane, the grid needs to be 'on' all of the time.").

${ }^{101}$ Noteworthy examples of R\&D aimed at testing Smart Grid concepts before their deployment in utility systems include the ongoing work at the National Renewable Energy Laboratory, NREL Brings Plug and Play to Smart Grid Testing, SmartGridNews.com (Jan. 31, 2012), http:// www.smartgridnews.com/artman/publish/Business_Strategy/NREL-brings-plug-and-play-to-

smart-grid-testing-4423.html, and the ambitious Pecan Street Project in Austin, Texas, PecAN StREET InC., http://www.pecanstreet.org/about/what-is-pecan-street-inc/ (last visited Jan. 22, 2013) (on file with the Harvard Law School Library).

${ }_{102}$ American Recovery and Reinvestment Act of 2009, Pub. L. No. 111-5, 123 Stat. 115 (2009). Funding for Smart Grid activities was $\$ 3.4$ billion for grid modernization which was matched one to one by industry for funding of almost $\$ 8$ billion. U.S. DEP'T OF ENERGY, 2010 SMART GRID RePORT 20 (2012), available at http://energy.gov/sites/prod/files/Smart\%20Grid\%20 Investment\%20Grant\%20Program\%20-\%20Progress\%20Report\%20July\%202012.pdf.

${ }^{103}$ See Sunil Sharan, Betting Smartly on the Smart Grid, GreenTech Media (June 22, 2010), http://www.greentechmedia.com/articles/read/betting-smartly-on-the-smart-grid/. See INST. FOR Elec. Efficiency, Utility-Scale Smart Meter Deployments (2011), available at http://www. edisonfoundation.net/iee/Documents/SmartMeter_Rollouts_0911.pdf, for a list of utilities and their rollouts.

${ }^{104}$ For a description of some projects supported by ARRA funding, see Jeffrey D. Roark, U.S. Government Support for Smart Grid, Elec. Power InST. (Dec. 1, 2011), available at http://www. hks.harvard.edu/hepg/Papers/New\%20Folder/Jeff_Roark.pdf. 
pricing of electricity. ${ }^{105}$ Dynamic pricing refers to any pricing structure that changes with the market price of electricity. ${ }^{106}$ There are many different flavors, with esoteric names such as "time of use,"107 "critical peak pricing," "variable peak pricing,"108 and "real-time retail pricing." 109 All have different mechanisms for calibrating consumers' rates to market prices. ${ }^{110}$ Dynamic pricing has been the source of experiments for decades, ${ }^{111}$ but it is not employed widely in the residential setting, although some large utilities have residential pricing plans with high enrollments. ${ }^{112}$ Dynamic pricing offers price signals to consumers so they can respond actively to changing conditions by, for example, reducing usage when rates go up.

This is dynamic pricing's Achilles heel: It can expose consumers to market risks. Although research to date suggests it will yield consumer savings, ${ }^{113}$ the conclusions are not definitive. Dynamic pricing has generated opposition from interest groups that believe their members' rates will increase under dynamic pricing structures. ${ }^{114}$ Research shows consumers can be satisfied with it once a

${ }^{105}$ Lawrence Berkeley Nat'l Lab., Chapter 5, in Smart Grid Technical Advisory Project, An Introduction - Smart Grid 10112 (2011) [hereinafter LBNL SMART GRID 101 CH. 5] (on file with the Harvard Law School Library) ("Are 'Smart Rates' necessary to achieve the benefits of Smart Grid? The answer is YES.").

${ }^{106}$ Regulatory Assistance Proj. Regulation Guide, supra note 95, at 55.

${ }^{107}$ See InSt. FOR Elec. EFFICIENCY, supra note 50, at 8-9.

${ }^{108}$ LBNL SMART GRID 101 CH. 5, supra note 105, at 7 ("Variable Peak Pricing (VPP) is a hybrid of time use and real-time pricing, where the rating periods are defined in advance but the prices are updated on a forecast basis.").

${ }^{109} I d$. ("For real-time retail pricing (RTP) tariffs, in an organized market, energy prices are typically linked to day-ahead or real-time energy markets and change hourly (or more frequently - e.g. every 30 minutes). In markets with vertically-integrated utilities that operate in regions without organized markets, real-time prices are typically set by the utilities administratively based on results from production cost models that reflect system conditions and estimate short-run marginal costs.").

${ }^{110}$ Regulatory Assistance Proj. Regulation Guide, supra note 95, at 55.

${ }^{111}$ LBNL SMART GRID 101 CH. 5, supra note 105, at 14 (noting that the "first tests of dynamic rates began in the early 1980's").

${ }_{112}$ See, e.g., Tariff Book, PACIFIC GAS \& ElEC., http://www.pge.com/tariffs/ERS.SHTML \#ERS (last visited Jan. 22, 2013) (on file with the Harvard Law School Library) (schedule of rates); John Farrell, Electricity Priced by the Hour Boosts Distributed Solar Value by a Third or More, Climate Progress (Jan. 26, 2012), http://thinkprogress.org/romm/2012/01/26/411434/ electricity-priced-by-the-hour-boosts-distributed-solar-value-by-a-third-or-more/ (discussing how PG\&E's dynamic pricing promotes solar power systems). Dynamic pricing has been more successful for industrial and commercial users of electricity. LBNL SMART GRID 101 CH. 5, supra note 105 , at 10 .

${ }^{113}$ See generally FARUQUI ET AL., supra note 68. A possible alternative to reduce risk might be a flat-fee pricing structure. Consumers would accept conditions such as more frequent direct load control. In return, they might have the option of flat-rate pricing for electricity, as long as they did not exceed a prescribed threshold amount of use. This could eliminate the need for dynamic pricing, simplify pricing options, and minimize consumer risk. See, e.g., PeCAn St. ProJ., supra note 26, at 18.

${ }_{114}$ Richard J. Pierce, Jr., The Past, Present and Future of Energy Regulation, 31 UTAH Envtl. L. Rev. 291, 303 (2011); Testimony of Rik Drummond Before the House Committee on Science, Space, and Technology 12 (Sept. 8, 2011), available at http://science.house.gov/sites/ republicans.science.house.gov/files/documents/hearings/090811_Drummond.pdf ("I predict the consumers, especially those within one of the largest voting blocks, baby boomers on a fixed income, will react negatively to even minor cost increases caused by various regulations and technical enhancements to the power grid."). A notable example of interest group opposition is 
program is underway, but other studies show dynamic pricing is unpopular (particularly when it leads to high peak rates) and does not yield effective results. ${ }^{115}$ On the basis of these uncertainties, in several high-profile cases, PUCs rejected dynamic pricing programs on the basis of risk to consumers. ${ }^{116}$

\section{Other Concerns}

Some consumers have other complaints about smart meters that have reduced the pace of PUC approval processes. They believe they are nefarious devices that control electricity use, ${ }^{117}$ pose health risks, ${ }^{118}$ or even are part of secret government plans to snoop on them. ${ }^{119}$ Like the original objections to ecommerce, these concerns may seem quaint a decade from now. However, opponents have used these arguments to gain some traction and slow the Smart Grid's progress in some cases. ${ }^{120}$

\section{E. Energy Law Federalism Poses a Challenge to Federal-State Cooperation in Building the Smart Grid}

The involvement of state PUCs in building a Smart Grid, and their often tense relationship with the federal government, makes the Smart Grid different from any previous attempt at building networks.

Both the states and the federal government have jurisdiction over parts of the Smart Grid. Depending on which part of the system is involved, either

that of the AARP. See, e.g., Maureen West, Consumer Advocates Question the Benefits of Smart Meters, AARP, Mar. 1, 2011, http://www.aarp.org/politics-society/advocacy/info-03-2011/smartmeter-benefits-questioned-az.html.

${ }^{115}$ LBNL SMART GRID 101 CH. 5, supra note 105, at 14; Vandenbergh \& Rossi, supra note 53 , at 1541 .

${ }^{116}$ See Application for Rehearing of Baltimore Gas and Electric Company, Order No. 9208, Pub. Util. Comm'n of Md. 1, 26 (2010).

${ }^{117}$ Compare Smart Grid Consumer Collaborative, supra note 62, at 8 ("Consumers do not always view benefits the same way as utilities believe they will and are wary of utility motives."), with Leslie Kaufman \& Kate Zernike, Activists Fight Green Projects, Seeing U.N. Plot, N.Y. TIMEs, Feb. 3, 2012, http://www.nytimes.com/2012/02/04/us/activists-fight-green-projects-seeingun-plot.html?pagewanted=all (quoting a protester as saying, "[t]he real job of smart meters is to spy on you and control you — when you can and cannot use electrical appliances.").

118 See, e.g., Mike Ludwig, Smart Meter Scoop: California Utility Launches Opt-Out Program, TRUTHOUT (Feb. 3, 2012) http://www.truth-out.org/smart-meter-scoop-california-utilitylaunches-opt-out-program/1328294529 (discussing the California opt-out ruling about "controversial smart meters"); see also N.Y. Pub. SERv. CoMm'N, supra note 23, at 35 (noting that "the RF emission levels of [smart meters] are exceedingly small relative to other commonly used devices (e.g., cellular telephones)").

${ }_{119}$ Doug Peeples, Smart Meters: Illegal, Dangerous, Un-American? Must Be True - It's on YouTube, SMARTGRIDNews.COM (Aug. 10, 2011), http://www.smartgridnews.com/artman/publish/ Technologies_Metering/Smart-meters-Illegal-dangerous-un-American-Must-be-true-it-s-on-YouTube-3902.html (quoting a YouTube video called "Smart Meters" in which the narrator describes smart meters as power company surveillance devices).

${ }^{120}$ In 2011, Marin County, California, banned smart meters in its unincorporated areas. Debra Kahn, California County Criminalizes Smart-Meter Installations, N.Y. Times, Jan. 5, 2011, http://www.nytimes.com/gwire/2011/01/05/05greenwire-calif-county-criminalizes-smart-meterinstalla-66649.html. 
FERC, a state PUC, or the governing council or board of a municipal or cooperative utility has jurisdiction. As noted above, state PUCs have authority to approve Smart Grid projects and cost recovery proposals for distribution utilities that make retail sales of electricity.

Yet the Smart Grid requires coordination of efforts between the different levels of government, and perhaps even a new distribution of regulatory authority. ${ }^{121}$ If FERC attempted to change the existing distribution of authority between it and the states (for example, by setting national interoperability standards that the states would be required to force utilities to adopt in individual projects), it could exacerbate the well-documented tension between the federal and state governments in electric utility regulation. ${ }^{122}$

Addressing and resolving this tension makes standards development an early and highly significant test of how participants will establish their expectations about Smart Grid governance. Decisions made now about standard-setting powers will set precedents that may well be hard to reverse.

\section{A New Regulatory Framework for the Smart Grid: INTEROPERABILITY STANDARDS}

Early Smart Grid experiments may lead to new business models and further growth, ${ }^{123}$ but numerous barriers exist to its rapid expansion. As a result, a fully robust network is many years away, and everything needed to support it is in the embryonic stage. ${ }^{124}$ Along the way, learning will be expensive.

The same spirit of dynamic, distributed, and meritocratic innovation that extends to Smart Grid technologies should characterize our approach to the federal and state regulatory environment. Smart Grid regulation should be flexible and facilitate a wide range of applications and new businesses. Such regulation would be smart, but the current system is not. The rules for building a new network have no precedent in modern life or in electric utility regulation. Unlike the Internet, where commerce followed technology, the Smart Grid aims to overhaul an existing network that gives utilities monopolies and guarantees their rates of return. This system is ill-suited to encouraging progress today. Smart Grid regulation must evolve to address the titanic clash looming at every node on the network between the staid utility industry and the transformative force of modern innovation. ${ }^{125}$

${ }^{121}$ See SGIP, Smart Grid Conceptual Model 8 (2010) ("The transition to the Smart Grid introduces new regulatory considerations, which may transcend jurisdictional boundaries and require increased coordination among federal, state, and local lawmakers and regulators.").

122 See generally Rossi \& Vandenbergh, supra note 53.

${ }^{123}$ Smart Grid Initiatives and Technologies: Hearing Before the Senate Committee on Energy and Natural Resources, supra note 3, at 8 (noting that "it is too early to assess the 'lessons learned"").

${ }^{124}$ BROWN ET AL., supra note 61, at 93.

${ }^{125}$ See Peter Fox-Penner \& Heidi Bishop, Mission, Structure, and Governance in Future Electric Markets: Some Observations, 89 OR. L. REv. 1107, 1111 (2011) ("[W]hat we have today is a collision between public mandates that promote active or tacit vertical integration 
A significant near-term test of regulatory evolution involves the development of interoperability standards. Many participants believe these are a necessary foundation for the Smart Grid. ${ }^{126}$ The ARRA accelerated the push for standards, requiring federally funded projects to use "open" standards "if available and appropriate." 127 Decisions about these standards are about far more than superior technical merit. Standards will have a considerable impact on the Smart Grid's architecture. They will decide how utilities' systems and smart meters will "talk" to one another, how the grid will foster DR and DG, ${ }^{128}$ how electric vehicles will plug into and communicate with the grid, how consumers' home networks will integrate energy management capabilities, and much, much more. ${ }^{129}$ Like the Phoenician alphabet or Internet protocols, standards for the Smart Grid promise to eliminate barriers to interactions, while defining how those interactions take place. Choices about standards will shape the course of innovation, and even the most basic and fundamental choices will have enormous consequences. These important choices are also difficult, because a network under construction is hard to standardize.

Two major tensions characterize Smart Grid standard-setting. The first is that industry participants steeped in the decades-long traditions of technical standards development and with prior experience with reliability standards will expect the private sector to lead standards development. Notwithstanding that strong preference for standards developed by private sector experts, setting Smart Grid interoperability standards requires a national effort to coordinate the many actors and establish the basis for their interaction. There are also specific national objectives (notably, ensuring cybersecurity) too important to be left to the private sector.

The second tension, introduced above in Part II, involves the unique landscape of Smart Grid stakeholders and their impact on standard-setting. We are attempting to regulate and encourage innovation on a network that already has extensive commercial use and entrenched actors with monopoly control over part of it. Two different types of actors require careful consideration. The first is the utilities themselves. Encouraging them to collaborate with vendors and other participants in standard-setting could exacerbate their monopoly power and create a disadvantage for future entrants, even if near-term decisions appear

alongside a disruptive technological change that is prompting new calls for retail deintegration and deregulation.").

${ }^{126}$ See, e.g., Empowering Consumers and Promoting Innovation through the Smart Grid: Hearing Before the Subcommittee on Technology and Innovation of the House Committee on Science, Space, and Technology, 112th Cong. 5 (2011) (statement of Donna Nelson, Chairman, Pub. Util. Comm'n of Tex.) (calling for "the creation of a national set of standards that can provide direction for utilities, industry and market participants").

${ }^{127}$ American Recovery and Reinvestment Act of 2009, Pub. L. No. 111-5, § 405(3), 123 Stat. 144 (to be codified at 42 U.S.C. $§ 17384(\mathrm{~b})(3)(\mathrm{F})$ ).

${ }^{128}$ Alison C. Graab, The Smart Grid: A Smart Solution to a Complicated Problem, 52 WM. \& MARY L. ReV. 2051, 2054 (2011).

${ }^{129}$ NIST FRAMEWORK 2.0, supra note 5, at 31. 
facially neutral. ${ }^{130}$ A difficult issue, then, is striking the democratic balance between utilities and other stakeholders to overcome any possible capture of the process.

The second important set of actors is the state PUCs. Because their nearterm decisions (not those of the marketplace) will determine what interoperability standards are adopted, providing guidance to them is important. As noted above in Part II, the prospect of any federal involvement in standardsetting cannot be considered in isolation, but must be viewed through the lens of contemporary energy law federalism. ${ }^{131}$

\section{A. The Need for Standards and the Foundation of "Interoperability"}

There are so many possible interactions and uncertainties in the Smart Grid that a foundation of standards is essential to specify how these interactions take place. ${ }^{132}$ Without standards, trying to exchange information among utilities, vendors, regulators, and others, never mind linking thousands of utility systems together, would be a veritable "Tower of Babel."133

The Smart Grid's complexity is staggering, with multiple domains and thousands of actors connected in complex paths and subnetworks. ${ }^{134}$ There are well over 100 points of interaction between subsystems in the NIST Smart Grid conceptual model ${ }^{135}$ and substantial variety in proposals for interactions at individual points. For example, should the "smart" interface between a residential customer and her utility be in a smart meter or in a different device that communicates directly with the network and the utility? ${ }^{136}$ This difficult and com-

${ }^{130} \mathrm{Wu}$, supra note 7, at 149 ("Neutrality, as a concept, is finicky, and depends entirely on what set of subjects you choose to be neutral among. A policy that appears neutral in a certain time period, like 'all men may vote', may lose its neutrality in a later time period, when the range of subjects is enlarged.").

${ }^{131}$ See, e.g., FERC Smart Grid Policy, supra note 23, If 13 (noting that there is "a tension that the Proposed Policy Statement raises between federal jurisdiction and state jurisdiction . . . [with respect to] both standards adoption and applicability and whether deployed technology will be subject to state or federal rate authority").

${ }^{132}$ A useful comparison is to convergence in communications industries. Werbach, supra note 11, at 207 ("Communications regulation developed as a series of isolated silos covering broadcasting, telephone networks, cable television, wireless communications, and other services. Now those networks are converging. When everything can be reduced to an interchangeable digital bit, standards define how information flows across the interconnected network of networks.").

${ }^{133}$ Util. Standards Bd., Smart Grid: Interoperability and Standards 5 (2008).

${ }^{134}$ NIST FRAMEWORK 2.0, supra note 5, at 38-42; see also Werbach, supra note 11, at 182 (noting that "[n]etworks are non-linear, in that there are typically multiple potential paths between two nodes, making the behavior of the networked system surprisingly complicated").

${ }_{135}$ Mass. InSt. OF TECH, supra note 1 , at 205.

${ }^{136}$ See, e.g., ZigBee Alliance, ZigBee Smart Energy Profile Specification 10-12 (2008) (containing graphic demonstrations of the different architectures); EMETER, VIEWS ON SMART METERS: END USE PERSPECTIVE (2011), available at http://cat-iqconference.com/files/2011/09/AliciaCarrosco-his-11-09-20-CAT-iq-plan-Smart-Metering-End-User-Perspective.pdf (observing that "the communications may be directly between the SM and smart appliances or through a gateway, or potentially both"). 
plicated question is one of literally thousands that interoperability standards address.

Standards do more than make interaction possible. They can resolve confusion and promote investments in technology, giving firms the confidence to market products that meet the standards. ${ }^{137}$ An open architecture can eliminate market obstacles, provide for competition among vendors, and encourage new third-party entrants. ${ }^{138}$ This can ensure more rapid adoption of the underlying technologies and benefits for consumers. ${ }^{139}$ If designed appropriately, standards can protect investments in legacy infrastructure by ensuring compatibility with older technologies as newer ones are deployed. ${ }^{140}$ By definition, however, standards standardize, and they eliminate some opportunities for innovation. ${ }^{141}$ Standards could lead to suboptimal decisions if their establishment shuts out tomorrow's more advanced technologies ${ }^{142}$ or freezes out potential new firms.

Should we wait until ongoing Smart Grid projects yield valuable evidence about what works and what does not? With so many uncertainties, the risk of proceeding without foundational standards outweighs other risks. ${ }^{143}$ Some standards can be flexible and account for future upgrades, mitigating the risk of being stuck with outdated technologies. Lessons learned from pilot projects can yield valuable knowledge that can be incorporated into newer versions of standards. ${ }^{144}$

\section{Basic Concepts Behind Interoperability Standards}

A "standard" includes "specifications that establish the fitness of a product for a particular use or that define the function and performance of a device or system." 145 Standards are technical documents that discuss requirements of

${ }^{137}$ NAT'L SCI. AND TeCh. Council, supra note 3, at 26-27.

${ }^{138}$ GridWise Architecture Council, supra note 8, at 21 ("Open standards can encourage a competitive, multi-supplier environment.").

${ }^{139}$ NIST FRAMEWORK 2.0, supra note 5, at 15-16; Chiao, Lerner, \& Tirole, The Rules of Standard-setting Organizations: An Empirical Analysis 2-3 (Ctr. For Economic Policy Research, Discussion Paper No. 6141, 2007).

${ }^{140}$ NAT'L SCI. AND TeCh. Council, supra note 3, at 26; see also Chiao et al., supra note 139, at 3 ("A standard that demands backwards compatibility can insure ongoing revenues for a legacy product for many years.").

${ }^{141}$ Quinn \& Reed, supra note 64, at 840 (noting that "regulatory decisions at this nascent stage of smart grid development will unavoidably widen some avenues of innovation while foreclosing others").

${ }^{142}$ BROWN ET AL., supra note 61, at 89 n.97 ("In theory, one could make the exact opposite argument, namely, that interoperability standards could impede progress in technology by forcing a kind of lowest common denominator factor into interoperability standards, particularly in regard to communications.").

${ }^{143}$ Werbach, supra note 11 , at 211 (noting that "the greatest threat to market-driven innovation in convergence industries is not what is clearly prohibited, but what is uncertain").

${ }^{144}$ NIST FRAMEWORK 2.0, supra note 5, at 175 ("As the experiences with new Smart Grid technologies are gained from these projects, NIST will use these lessons learned to further identify the gaps and shortcomings of applicable standards.").

${ }_{145}$ NIST FRAMEWORK 2.0, supra note 5, at 22. 
minimum quality and the testing and certification of compliant products. ${ }^{146}$ They take many forms. They may be normative (specifying "fully fledged implementable standards or safety and security practices"), guiding (providing "information on best practices"), or informative (providing "context and background information on Smart Grid technologies, practices and policies"). ${ }^{147}$

Interoperability standards are different from standards for one product. ${ }^{148}$ They are foundational to networks, specifying parameters of how actors and components throughout the network interact with each other. ${ }^{149}$ Interoperability's fundamental attribute is the ability of users and devices to communicate with each other transparently, without special effort. ${ }^{150}$ The familiar "WiFi" standard (actually a part of a standard) is an excellent example of an interoperability standard. It specifies the foundation for wireless local area network protocols, making it possible for a user to access these networks without specifying the details of how her computer communicates with the network system. ${ }^{151}$

To achieve interoperability in the Smart Grid, we are starting virtually from scratch, with hundreds of standards needed, ${ }^{152}$ and no common understanding of foundational matters such as what types of data are gathered or how they are exchanged. ${ }^{153}$ Talking about these matters is meaningless without grounding them in a broader context. It is impossible to talk about data without knowing what we are trying to accomplish with that data. Decisions about interoperability, then, are related to fundamental regulatory decisions.

\footnotetext{
${ }^{146}$ Technical standards are different from "performance standards," such as those employed in the environmental setting, that set goals and objectives for those regulated by them. See Werbach, supra note 11, at 195; see also 15 U.S.C.A. $\$ \$ 272,4301$ (a)(9) (West 2012) (defining "technical standards").

${ }^{147}$ SGIP, StANDARDS CATAlog 2 (2011), available at http://collaborate.nist.gov/twiki-sggrid/ pub/SmartGrid/SGIPGBDocumentsUnderReview/Standards_Catalog_Process_and_Structure_ V0_9_20110401.pdf [hereinafter SGIP STANDARDS CATALOG].

${ }_{148}$ For a discussion of the impact of environmental product standards, see Noah Sachs, Can We Regulate Our Way to Energy Efficiency? Product Standards as a Climate Change Policy, 61 VAND. L. REV. 1631 (2012).

${ }^{149}$ Werbach, supra note 11 , at 197.

${ }^{150}$ NIST defines "interoperability" as "[t]he capability of two or more networks, systems, devices, applications, or components to exchange and readily use information - securely, effectively, and with little or no inconvenience to the user." NIST FRAMEWORK 2.0, supra note 5, at 6. See generally GridWise ArChitecture Council, supra note 8, at 13-14 (discussing different levels and attributes of interoperability).

${ }^{151}$ See IEEE 802 LAN/MAN Standards Committee, IEEE 802, http://www.ieee802.org/ (last visited Jan. 22, 2013) (on file with the Harvard Law School Library). Ethernet was first introduced in 1980 as a result of collaboration among three companies building upon work in the 1970s by computer scientists. The Ethernet: A Local Area Network 1 (1980), available at http://ethernethistory.typepad.com/papers/EthernetSpec.pdf; Leiner et al., supra note 30. This family of standards was standardized through the work of SDOs, including IEEE. Development of Ethernet Standards, ETHERmanage.com, http://www.ethermanage.com/ethernet/10quickref/ ch1qr_4.html (last visited Jan. 22, 2013) (on file with the Harvard Law School Library).

${ }_{152}$ See NIST Framework 2.0, supra note 5, at 22.

${ }^{153}$ FERC Technical Conference 2011, supra note 10 (statement of George Arnold), at 13 ("[I]nteroperability in the smart grid requires a common language of data models and identifiers to enable communication across systems and applications.").
} 
The technical challenges are daunting. Even a common vocabulary is hard to come by, as different technical disciplines use terms such as "reliability" in different ways. There is a spectrum of potential interaction among devices and systems. For example, two devices could be only physically connected, or have the ability to exchange data, or coordinate operations based on complex communication protocols and applications. ${ }^{154}$ The approach will be different at various locations on the Smart Grid. At some points, the quality of interaction might be loosely defined, but at others it might be tightly governed. ${ }^{155}$ The technology to accomplish interactions (as in the case of DG) is often not fully mature. Integrating legacy utility infrastructure, which generally lacks standardization, complicates matters further.

\section{Conceptual Models and "Use Cases"}

The breathtaking complexity of achieving interoperability in the Smart Grid is such that an agreed-upon vision of Smart Grid architecture is essential simply to get started. Tools such as semantic models, ${ }^{156}$ use cases, and conceptual models ${ }^{157}$ illustrate a wide range of interactions and serve as a foundation for standards. Choices made now, based on these models, are some of the most important decisions that will ever be made about the Smart Grid.

${ }^{154}$ GridWise Architecture CouncIL, supra note 8, at 23-25. The GWAC hierarchical conceptual model of different levels of interoperability, known colloquially as the "GWAC stack," is widely followed in Smart Grid standards development. NIST FrAMEWORK 1.0, supra note 1, at 30 .

${ }^{155}$ Werbach, supra note 11, at 207 (Network standards play a "complicated role" and "a relatively lightweight standard at the interface between key layers of the network may allow for great variety on either end.").

${ }^{156}$ Elec. Power Research Inst., Report to NIST on the Smart Grid Interoperability STANDARDS RoADMAP vi (2009), available at http://www.nist.gov/smartgrid/upload/Report_to_ NIST_August10_2.pdf [hereinafter EPRI NIST REPORT] (noting that a common semantic model for information is a high priority for the Smart Grid).

${ }^{157}$ NIST FRAMEWORK 2.0, supra note 5, at 38-42 (describing the NIST conceptual model of the Smart Grid). 
Figure 1: NIST Conceptual Model for SMARt Grid ${ }^{158}$

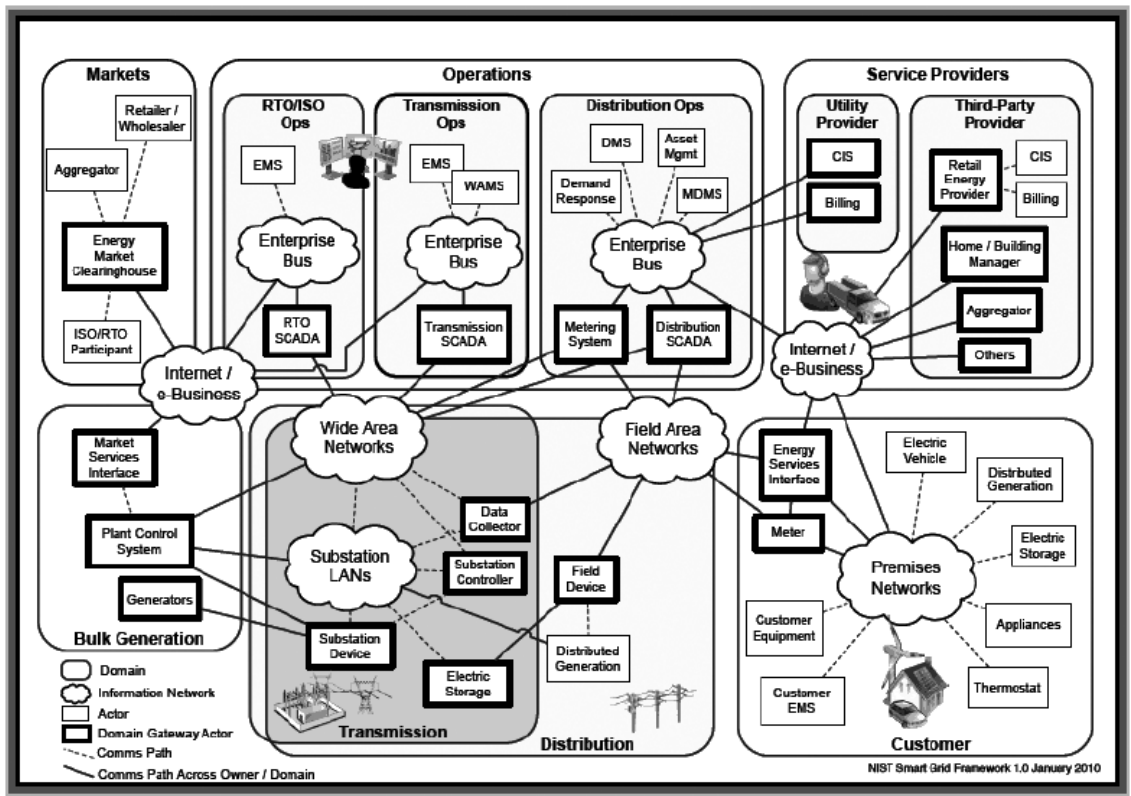

"Use cases," as the name suggests, are narrative descriptions of how actors will interact in ("use") the Smart Grid. A standard would enable these uses by specifying the required technical content. The SAE International ("SAE") standard J2836 for "vehicle-to-grid" connections ${ }^{159}$ specifies five different scenarios under which a vehicle owner could connect to the electrical grid to obtain power, or, possibly, provide power back from her battery to it. Under the use "U2," for example, a vehicle battery is used in a utility's direct load control program. ${ }^{160}$

\footnotetext{
${ }^{158}$ NIST FRAMEWORK 1.0, supra note 1, at 35.

${ }^{159}$ See generally SAE Int'L, Use Cases for Communication Between Plug-in Vehicles AND THE UTILITY GRID (2010), available at http://standards.sae.org/j2836/1_201004/.

${ }^{160}$ See Theodore Bohn, U.S. Dep't of Energy, Challenges of the Coming Electric CAR Revolution 34 (2011), available at http://www.ilmua.org/AnnualMeeting/Annual\%20Meeting\%202011_Bohn.pdf.
} 
Figure 2: Example of A "Use Case" 161

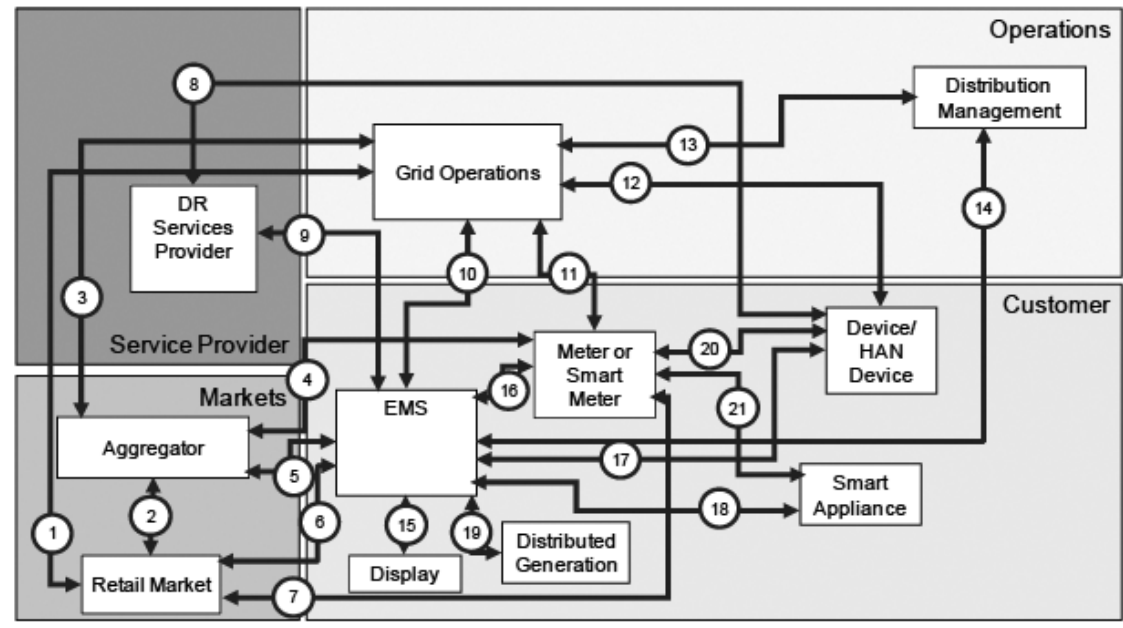

Demand Response Use Cases: Actors and Logical Interfaces

HAN: Home Area Network

EMS: Energy Management System

DR: Demand Response

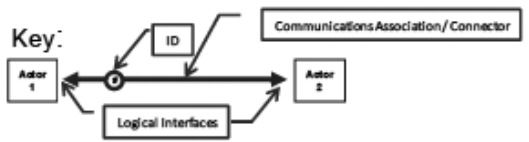

Some caution is in order, as the apparent comprehensiveness of a set of use cases may be illusory if some known interactions are excluded. ${ }^{162}$ Also, if today's Smart Grid is like the Internet of 1995, we cannot foresee all future new uses. Someone will come along at a later date and draw new lines, squiggles, or 3-D connections on a conceptual model, making connections previously thought impossible. However, we have to have some common frame of reference, which the use cases and conceptual models provide.

\section{B. How Standards Are Set}

A use case is descriptive, not normative. It identifies specific interactions that can take place across the Smart Grid, but does not prescribe how they happen. That leaves an important issue unsettled: who sets the standards' content? There is no obvious answer. We are defining what it is while we are doing it, and could make big and expensive mistakes early and often.

${ }^{161}$ A use case is a graphical representation of the inputs, processes, outputs and responsibilities of actors in the system for demand response. See EPRI NIST RePort, supra note 156 , at 55.

${ }_{162}$ See Chuck Goldman \& Rogery Levy, Engaging the Customer, LAwrence Berkeley Nat'l Lab., Smart Grid Technical Advisory Project (2009), available at http://collaborate. nist.gov/twiki-sggrid/bin/view/SmartGrid/PAP10EnergyUsagetoEMS (download from icon "NARUC-Webinar2-Dec16-FinalDraft-121609.ppt") (detailing possible problems with use cases). 
With hundreds of standards to be set, a regularized process is necessary to avoid uncertainty. ${ }^{163}$ Where we start, and how we proceed, are extremely important decisions.

\section{The Norm: Standard-setting By Private Sector Experts (Standards Development Organizations)}

There is a strong preference in the United States for "bottom up,"164 participant-driven, private sector standard-setting processes. Many different types of groups develop standards, including formal organizations with rigorous procedures, industry consortia, and other actors. ${ }^{165}$ A standard can also evolve without any action if a technology becomes so prevalent that it becomes the de facto standard. 166

Formal "standards development organizations" ("SDOs") such as the IEEE and SAE have decades of expertise in developing voluntary consensus standards. "Consensus" refers both to the process of developing standards, and to the acceptance of certified products in the marketplace. A manufacturer desiring to produce a specific grade of steel, for example, will refer to a standard set by the ASTM for the content of specific ingredients and the production process to guarantee quality.

This type of standards organization is well known to utilities and other Smart Grid participants. ${ }^{167}$ Major SDOs already have standards in place for some important Smart Grid technologies. One notable example is the IEEE 802 family of standards, which includes the foundation for the familiar "WiFi" wireless local area network protocols, among others. ${ }^{168}$ SDOs are developing standards, often in competition with one another, which they intend to become part of the Smart Grid. ${ }^{169}$ These standards vary in their availability and maturity. ${ }^{170}$ Some existing standards have been modified for the Smart Grid by addressing new issues. However, some either exist only in draft form, or would be new and developed specifically for the Smart Grid. ${ }^{171}$

${ }^{163}$ NIST SGIP, SMart Grid InTeroperability PANel Standards 6 (2010), available at http://www.narucmeetings.org/Presentations/SGIP\%20Update_2010_NARUC\%20Summer_v81. pdf (noting that "[c]onsistent action will influence the vendor community").

${ }^{164}$ NAT'L SCI. AND TeCH. Council, supra note 3 , at 4.

${ }^{165}$ NIST FRAMEWORK 2.0, supra note 5, at 22.

${ }^{166}$ Stacy Baird, The Government at the Standards Bazaar, 18 Stan. L. \& PoL'y Rev. 35, 49 (2007).

${ }^{167} I d$. at 42 (noting that "standards development organizations are exceedingly credible and common to all industries that rely on standards").

${ }^{168}$ See IEEE 802, supra note 151; see also Leiner et al., supra note 30 . The WiFi family of standards was standardized through the work of SDOs, including IEEE. ETHERMANAGE.COM, supra note 151 .

169 See Pac. Nw. Nat'l Lab., Home Area Networks and the Smart Grid 1 (2011) (noting that " $[\mathrm{t}]$ here are myriad standards and protocols vying for dominance in the smart grid market").

${ }_{170}$ Opening Remarks to FERC Technical Conference 2011, supra note 10, at 3.

${ }^{171} I d$. 
SDOs are indispensable to developing interoperability standards. ${ }^{172}$ Participants' experience with them also creates a strong expectation about how standards are set. SDOs have formal participatory "processes marked by openness, balance, transparency, and characterized by due processes to address negative comments."173 They typically involve their industry members in committees to draft new standards and submit them to the membership for approval. ${ }^{174}$ This can be as complex as the workings of any legislature, with rules governing the composition of committees, voting procedures, and other matters. As a result, SDOs are generally "perceived to provide a more effective 'stamp of approval' than special interest groups dominated by technology sponsors." 175

The American National Standards Institute ("ANSI") is the designated national standards body, ${ }^{176}$ and itself an SDO that accredits other SDOs. Under its "Procedures for the Development and Coordination of American National Standards," 177 the ANSI seeks "to verify that the principles of openness and due process have been followed and that a consensus of all interested parties has been reached." 178 The threshold for developing a standard is "sufficient evidence that the standard has a substantive reasonable basis for its existence and that it meets the needs of producers, users and other interest groups." 179 The SDO must follow procedures designed to ensure that the standard is a product of a consensus judgment that subordinates any one stakeholder's narrow economic interest. ${ }^{180}$ These include requirements that the SDO have balanced representation from interested parties, that votes cannot be dominated or manipulated by those with economic interests or other influence, and that dissatisfied parties may appeal adverse decisions. ${ }^{181}$ An important ANSI-accredited SDO that sets standards for utilities is the North American Energy Standards Board ("NAESB"). ${ }^{182}$ NAESB was expanded from a predecessor

172 The EISA recognizes this by directing NIST to work with specified SDOs. See EPRI NIST REPORT, supra note 156 , at vi.

${ }^{173}$ NIST FRAMEWORK 1.0, supra note 1 , at 45.

${ }^{174}$ See Membership, ASTM INT'L, http://www.astm.org/MEMBERSHIP/standardsdevelop. html (last visited Jan. 22, 2013) (on file with the Harvard Law School Library).

${ }^{175}$ Chiao et al., supra note 139 , at 3.

176 Am. Nat'l Standards Inst., Overview of the U.S. Standardization System, available at http://publicaa.ansi.org/sites/apdl/Documents/News\%20and\%20Publications/Brochures/ U.S.\%20Standardization\%20System-07.pdf.

${ }^{177} I d$.

${ }^{178}$ Amy A. Marasco, Standards Development: Are You at Risk?, Am. Nat'L Standards INST., http://www.ansi.org/news_publications/other_documents/risk.aspx?menuid=7 (last visited Jan. 22, 2013) (on file with the Harvard Law School Library).

${ }^{179} \mathrm{Id}$.

${ }^{180}$ EPRI NIST REPORT, supra note 156 , at 10.

${ }^{181}$ See Marasco, supra note 178; see also BROWn ET AL., supra note 61, at 65 (noting the line of Supreme Court cases that "emphasize[s] that industry standards must be developed and administered objectively, and not by a company or group that has a vested interest in an exclusionary outcome").

${ }^{182}$ See About NAESB, N. Am. EnERGy Standards BD. http://www.naesb.org/aboutus.asp (last visited Jan. 22, 2013) (on file with the Harvard Law School Library). 
organization in 2002 to develop standards for the wholesale gas and electric markets. ${ }^{183}$

The pluralistic ideal of SDO democratic engagement can break down in practice if companies co-opt the process by embedding content in standards that favors their interests. ${ }^{184}$ This concern has led to criticism of SDO standardsetting as regulation outsourced to the private sector without appropriate checks, ${ }^{185}$ and discussion about the antitrust impacts of potential competitors uniting to define and dominate an industry. ${ }^{186}$ However, there is a strong preference in federal law for private standards development. The ANSI's "United States Standards Strategy" states that "[v]oluntary consensus standards are at the foundation of the U.S. economy." 187 The National Technology Transfer and Advancement Act ("NTTAA") requires federal agencies to "use technical standards that are developed or adopted by voluntary consensus standards bodies."188 OMB Circular A-119 elaborates the definitions and requirements for voluntary consensus standards. ${ }^{189}$

\section{An Alternative Form of Standard-setting: Crowdsourcing (Internet Standards)}

An alternative standard-setting model is the highly decentralized structure for setting the Internet's technical standards. The main Internet standards organizations are the Internet Engineering Task Force ("IETF") 190 and World Wide

${ }^{183}$ See Letter from Jonathan Booe, Deputy Director, NAESB, to Dr. Patrick Gallagher, Director, NIST (Feb. 7, 2011) (on file with the Harvard Law School Library), available at http:// www.nist.gov/standardsgov/upload/NAESB.pdf; William P. Boswell \& James P. Cargas, North American Energy Standards Board: Legal and Administrative Underpinnings of a Consensus Based Organization, 27 ENERGY L.J. 147 (2006) (discussing the NAESB's creation). FERC incorporates by reference NAESB business practice standards for the wholesale power system. See, e.g., Incorporation by Reference of North American Energy Standards Board Wholesale Electric Quadrant Standards, 18 C.F.R. § 38.2 (2010); FERC, Standards for Business Practices of Interstate Natural Gas Pipelines, RM96-1-036, 140 FERC II 61,036 (July 19, 2012).

${ }^{184}$ Sidney A. Shapiro, Outsourcing Government Regulation, 53 DuKE L.J. 389, 406-11 (2003) (discussing potential for individual actors' dominance of private SDOs); Chiao et al., supra note 139, at 6 (noting that standard-setting can involve a "war of attrition" in which "vested interests" delay a standard). See generally Tyler R.T. Wolf, Existing in a Legal Limbo: The Precarious Legal Position of Standards-Development Organizations, 65 WASH. \& LeE L. Rev. 807 (2008) (discussing this issue and more alleged defects of the SDO process).

185 See generally Shapiro, supra note 184.

${ }^{186}$ Mark A. Lemley, Antitrust and the Internet Standardization Problem, 28 ConN. L. Rev. 1041 (1996) (discussing antitrust concerns and private standards organizations); see also Standards Development Organization Advancement Act of 2004, Pub. L. No. 108-237, 118 Stat. 661 (2004)

${ }^{187}$ Baird, supra note 166 , at 55-56.

${ }^{188}$ National Technology Transfer and Advancement Act of 2004, Pub. L. No. 104-113, § 12, 110 Stat. 775 (1996).

${ }^{189}$ Office of Mgmt. \& Budget, Exec. Office of the President, OMB Circular No. A119, Revised Federal Participation in the Development and Use of Voluntary Consensus Standards and in Conformity Assessment Activities [hereinafter OMB Circular] $\S 4(\mathrm{a})(1)(\mathrm{v})$ (1998), available at http://standards.gov/a119.cfm.

190 See Paul Hoffman, The Tao of IETF: A Novice's Guide to the Internet EngineerING TASK FORCE 1 (2012), available at http://tools.ietf.org/rfcmarkup?doc=fyi17. 
Web Consortium ("W3C"). ${ }^{191}$ Neither relies on any government agency to administer standards. W3C membership is open to anyone, and the W3C process $^{192}$ is designed to produce standards that "maximize consensus" and "earn endorsement by W3C and the broader community." 193

The IETF's "radically decentralized and open structure"194 allows for the broadest exchange of views on standards, but it is doubtful that it is a good model for the Smart Grid. As one observer notes, the IETF is "rare in its ability to function so effectively" despite being fully decentralized. ${ }^{195}$ This has led at least one observer to conclude that the Internet crowdsourcing model is not a realistic one for the Smart Grid. ${ }^{196}$

Internet standards, however, will be important in the Smart Grid, ${ }^{197}$ and one cherished aspect of these standards is well worth emulating. A standard is "open" if a Fortune 500 company as well as a teenager in a garage in California can readily access it, design around it, and build new products. Internet standards are open and freely available, ${ }^{198}$ and those of the Smart Grid should be as well.

\section{Reasons to Depart from the Norm: Federal Standard-setting Involvement for the Smart Grid}

Private standard-setting may be the norm, but the difficulties of achieving any progress in developing Smart Grid interoperability standards seem insuperable unless the federal government is involved. ${ }^{199}$ With Smart Grid rollouts

${ }^{191}$ See WORLD WIDE Web Consortium, http://www.w3.org/ (last visited Jan. 22, 2013) (on file with the Harvard Law School Library) (stating that "[t]he World Wide Web Consortium (W3C) is an international community that develops open standards to ensure the long-term growth of the Web").

${ }^{192}$ WC3 Process Document, World Wide Web Consortium, http://www.w3.org/2005/10/ Process-20051014/tr (last visited Jan. 22, 2013) (on file with the Harvard Law School Library).

${ }^{193}$ Standards, World Wide WeB Consortium, http://www.w3.org/standards/ (last visited Jan. 22, 2013) (on file with the Harvard Law School Library).

${ }^{194}$ Werbach, supra note 11 , at 199.

${ }^{195} \mathrm{Id}$.

${ }^{196}$ FERC Technical Conference 2011, supra note 10 (statement of Andrew Wright), at 57 (stating that " $[\mathrm{t}]$ he most farthest-reaching [sic] imaginative thing would be to create a new standards organizations [sic], something like the IETF. That's probably unrealistic").

${ }^{197}$ NIST FRAMEWORK 2.0, supra note 5, at 48-49 (discussing the IETF's "RFC 6272 Internet Protocols for the Smart Grid" that "provide[ ] Smart Grid designers with guidance on how to use the Internet Protocol Suite (IPS) in the Smart Grid [and] provide[] an overview of the IPS and the key infrastructure protocols that are critical in integrating Smart Grid devices into an IP-based infrastructure").

${ }^{198}$ FERC TEChNICAL Conference 2011, supra note 10 (statement of Andrew Wright), at 41 (noting with respect to the first Smart Grid standards that " $[\mathrm{t}]$ he standards under consideration are open, in the sense that anyone can gain access to the standard, but they are not nearly as open or freely accessed as the IETF and W3C standards that can be downloaded free of cost and restrictions from many websites").

${ }^{199}$ See Baird, supra note 166, at 38 (noting that "[t]he high demand for interoperability is in turn creating an environment wherein stakeholders are more likely to turn to government to intervene in the market to aid in achieving particular goals more rapidly than may occur in the natural course of market activity"). 
underway, many believe that standards will not be in place quickly enough if left to the market.

\section{The Smart Grid's Massive Scope and Complexity}

The first reason to depart from the norm is the enormous scope of the Smart Grid, involving thousands of stakeholders ${ }^{200}$ and hundreds of standards that must be developed all at once. This requires a different standard-setting process $^{201}$ due to a lack of resources and coordination difficulties. ${ }^{202}$ A typical technical standard can take years to develop. ${ }^{203}$ The Ethernet standard for wired computer networking took ten years to ripen into a standard, and even longer to evolve into the more robust networking standard in wide use today. ${ }^{204}$ Multiply that by hundreds, and one begins to see the extraordinary breadth of the task.

The number of standards and prospect of delay are hardly the only concerns. Many SDOs have little to no experience with the electric utility industry, ${ }^{205}$ or with the impacts of their decisions on the electric grid. A recurring issue is the bridging of functionality across SDOs' respective areas of engagement. Setting Smart Grid standards often entails an "[a]nalysis of cross-functional area applications requiring coordination between one or more technologies beyond the original scope of the technology itself." ${ }^{206}$ Vehicle-togrid connections, for example, involve organizations developing electrical and automotive standards. These SDOs usually lack experience working with each other and coordinating their efforts will be difficult at best. ${ }^{207}$

\section{Federal Involvement is Necessary to Ensure Grid Reliability and Cybersecurity}

There are other reasons that innovation will be suboptimal without federal involvement. The electric grid has to work continuously, so some entity must be responsible for assuring reliability and that standards allow new devices to

${ }^{200}$ NIST FRAMEWORK 2.0, supra note 5, at 34 (noting the involvement of "thousands of companies" that may build products for the Smart Grid).

${ }^{201}$ EPRI NIST REPORT, supra note 156, at 18 (noting that "[t]he large number of stakeholders, different considerations, [and] number and complexity of standards available (and missing) requires a more formal nationally-driven governance structure"). 124-26.

${ }^{202}$ FERC Technical Conference 2011, supra note 10 (statement of Wayne Longcore), at

${ }^{203}$ Peter Fox-Penner, supra note 4, at 61 (standards groups "convene committees of engineers who wrangle, often for years, over a standard"); Chiao et al., supra note 139, at 3 (noting the "frequently ponderous pace at which traditional standards development organizations move").

${ }^{204}$ FERC Technical Conference 2011, supra note 10 (statement of Ed Beroset), at 59.

205 See Smart Grid Standards Adoption: Staff Update and Recommendations, FERC, slide 4 (Jul. 15, 2010), available at http://www.ferc.gov/legal/staff-reports/07-15-10-smart-grid.pdf (noting that standards setting in the SGIP involves "a broad range of stakeholders, many of whom have not previously been involved in the electric industry").

${ }^{206}$ NIST FRAMEWORK 2.0, supra note 5, at 130.

${ }^{207}$ See Energy Bar Association Panel Discussing the Smart Grid, 31 ENERGy L.J. 81, 91 (2009) (attributing to NIST Administrator George Arnold the observation that getting SDOs to work together is like "herding cats"). 
work with utilities' legacy equipment. The North American Electric Reliability Corporation ("NERC"), certified by FERC as the "Electric Reliability Organization," 208 plays an important role in this process. NERC conducts reliability assessments and enforces mandatory standards to ensure the reliability of the wholesale power system, in accordance with Section 215 of the Federal Power Act. ${ }^{209}$ NERC views it as critical that interoperability standards for the Smart Grid work with its reliability standards. ${ }^{210}$ This integration would be too difficult to leave to any one SDO.

Another worrisome issue is cybersecurity, which has emerged as a major Smart Grid concern. ${ }^{211}$ Increasing the points of interaction on the grid $^{212}$ and exchanging more information than before can lead to vulnerabilities. A 2012 report by the Department of Energy's Inspector General found that 36\% of Smart Grid projects receiving federal funds did not adequately discuss these risks, ${ }^{213}$ and a sweeping 2011 report from the Government Accountability Office ("GAO") criticized progress on cybersecurity. ${ }^{214}$ One key GAO finding is that no one entity oversees the entire grid to ensure that systems interoperate in a secure manner. The issue of institutional responsibilities for cybersecurity is important, and the subject of many ongoing discussions. ${ }^{215}$ This and other na-

${ }^{208}$ N. Am. Elec. Reliability CoRP., http://www.nerc.com/ (last visited Jan. 22, 2013) (on file with the Harvard Law School Library).

${ }^{209} 16$ U.S.C.A. $\$ \S 8240(a)(2)$, (c)(1) (West 2012). Under this section, FERC approves reliability standards that NERC develops and submits to it.

${ }^{210}$ N. Am. Elec. Reliability Corp., Comments of the North American Electricy RelLiability CORPORATION ON NIST Framework AND RoAdMAP fOR SMART Grid INTERoperABILITy STANDARDS, RELEASE 1.0 (DRAFT) 7-8 (Nov. 9, 2009) available at http://www.nerc.com/ docs/pc/sgtf/FinalNERCCommentsNIST_Smart_Grid_Framework_Document.pdf.

${ }^{211}$ See, e.g., Int'L Energy Agency, Technology Roadmap: Smart Grids 32 (2011), available at http://www.iea.org/publications/freepublications/publication/smartgrids_roadmap.pdf ("The introduction of information technologies in the smart grid introduces new cyber vulnerabilities that must be protected against by the rigorous application of cyber security standards."); Lance Witney, Billions to be Spent on Smart-Grid Cybersecurity, CNET (Feb. 4, 2010), http:// news.cnet.com/8301-1009_3-10447430-83.html.

${ }_{212}$ See Marsha W. Johnston, Smart Grid Initiatives Address Cyber Security, Renewable Energy Intermittency, RENEWABLEENERGYWORLD.COM (Jan. 25, 2012), http://www.renewableenergy world.com/rea/news/article/2012/01/smart-grid-initiatives-address-cyber-security-renewable-energy-intermittency (noting that renewable energy systems can be owned by consumers, not utilities, and therefore may pose cybersecurity risks).

${ }^{213}$ U.S. Smart Grid Projects Failing on Security, Info. Age (Jan. 27, 2012), http://www. information-age.com/channels/information-management/news/1687918/us-smart-grid-projectsfailing-on-security.thtml.

${ }^{214}$ See U.S. Gov't Accountability OfFice, supra note 14, at 22-25 (identifying six challenges to smart grid cybersecurity).

${ }^{215}$ See NIST, Guidelines for Smart Grid Cyber Security: Vol. 1, Smart Grid Cyber Security Strategy, Architecture, and High-Level Requirement (2010), available at http:// csrc.nist.gov/publications/nistir/ir7628/nistir-7628_vol1.pdf; NIST FRAMEWORK 2.0, supra note 5, at 126 (noting that NISTIR 7628 requires that "standards . . . undergo a thorough cybersecurity review”); Tom Baumeister, Literature Review on Smart Grid Cyber Security (2010), available at http://server.wattdepot.org/techreports/10-11/10-11.pdf (reviewing the literature on many subissues relating to cybersecurity). In September 2012, FERC created an "Office of Energy Infrastructure Security" to coordinate its cybsersecurity efforts. See New FERC Office to Focus on Cyber Security, FERC (Sept. 20, 2012), http://www.ferc.gov/media/news-releases/2012/ 2012-3/09-20-12.asp. 
tional concerns are too critical to be left to a single SDO. Nor does any one SDO have the ability to ensure that standards currently under development in Europe and China are harmonized with American standards. ${ }^{216}$

\section{Federal Involvement is Necessary to Provide Guidance to States and Overcome Federalism Barriers}

A final and important reason to have a federally-led standard-setting process is the involvement of state PUCs. As noted above, states, not the market, have the ultimate authority to determine whether to approve standards in projects affecting the distribution system. ${ }^{217}$ They will look to standards development processes for guidance. ${ }^{218}$ For the foreseeable future, they are the decision makers, and, given their pivotal role, they either have to be involved in the standard-setting process or have confidence in its outcome. Utilities need to know whether PUCs will support the process. It would be wasteful for utilities to commit their resources to a national process, and then have to face duplicative technical evaluations in state proceedings.

Yet it would be inappropriate to expect the states themselves to lead the standards development process. Many PUCs have limited staffs and lack the necessary technical expertise. ${ }^{219}$ Having 51 different points of approval may lead to balkanization, in which states choose different technologies and standards, and uniformity suffers. ${ }^{220}$ Companies seeking to participate in regional or national projects would face the excessive transaction costs of multiple approvals.

${ }^{216}$ See NIST FRAMEWORK 2.0, supra note 5, at 32-34 for a discussion of ongoing activities to "harmonize" standards at the international level.

${ }^{217}$ See, e.g., U.S. Gov't Accountability OfFICE, supra note 14, at 19 (“'[S]tate regulatory bodies and other regulators with authority over the distribution system will play a key role in overseeing the extent to which interoperability and cybersecurity standards are followed since many smart grid upgrades will be installed on the distribution system.”); N.Y. PUB. SERV. Comm'N, supra note 23, at 60 (stating that "we conclude that the states are free to act within their jurisdiction on the standards, without specific federal statutory direction or constraint").

${ }^{218}$ See, e.g., N.Y. Pub. SERv. ComM'N, supra note 23, at 61 ("We will look to the standards as a guide in our review of project proposals, and utilities should use them as a reference case of best practices.”); FERC Technical Conference 2011, supra note 10 (statement of Andy Bochman), at 98 (noting "there is a distinct possibility that state public utility commissions and other regulatory organizations might quickly promote [adopted standards] to fill what they see as a significant void in guidance").

${ }^{219}$ U.S. Gov't ACcountability OfFice, supra note 14, at 20 (noting with respect to PUCs that "limited resources and technical expertise made their roles in overseeing interoperability and cybersecurity, including participating in the NIST standards process, more challenging").

${ }^{220}$ See, e.g., Quinn and Reed, supra note 64, at 881-82; Margaret Ryan, Grid Week Analysis: Smart Grid Losing to EPA, AolEnergy (Sep. 19, 2011), http://energy.aol.com/2011/09/19/ gridweek-analysis-smart-grid-losing-to-epa/ (noting that this leaves the industry having to deal with "51 bar fights"). 


\section{The National Governance Structure Established and in Place for Smart Grid Standards Development}

The federal government's overriding national interests require it to oversee the Smart Grid standards-setting effort. ${ }^{221}$ The model of government as catalyst is an appropriate one for the Smart Grid, ${ }^{222}$ as the federal government has previously been a "public sector partner" and a "convener" in other standards development efforts. ${ }^{223}$ The federal role is to coordinate the effort, ensure that national issues are addressed properly, and leverage SDOs' efforts. In the Smart Grid, utilities and PUCs would expect to be involved in the standards process, as would other stakeholders. In particular, PUCs need to be reassured that the federal convening process does not compromise their long-standing authority to approve utilities' projects at the distribution level. Designing a standard-setting regime that overcomes any possible reluctance or resistance on the part of states requires their involvement in the process.

Displacing SDOs from their traditional role as the basic standard-setting entities would be inapt. No federal agency has the technical expertise to set Smart Grid standards, so it is important to take advantage of existing standards and SDOs' expertise. Relying on SDOs as primary standard setters would not run afoul of the doctrine "prohibiting delegations of social policymaking authority to private groups," as Professor Michael Froomkin puts it in his criticism of the process for assignment of Internet domain names. ${ }^{224}$ Froomkin notes, "[t]hat doctrine is not violated when the government relies on private groups to set technical standards." 225

\section{The NIST-led Process (Smart Grid Interoperability Panel)}

The EISA 226 addressed standards development in its Title XIII, which established a national framework for Smart Grid development and began with a

${ }^{221}$ Opening Remarks to FERC Technical Conference 2011, supra note 10, at 7.

${ }^{222}$ See id.; EPRI NIST Report, supra note 156, at 12, 18.

${ }^{223}$ NAT'L SCI. AND TeCh. Council, supra note 3, at 4; Aneesh Chopra and Patrick Gallagher, Public-Private Standards Efforts to Make America Strong (January 31, 2012), http://www. whitehouse.gov/blog/2012/01/31/public-private-standards-efforts-make-america-strong; Aneesh Chopra, Miriam Sopiro, Cass Sunstein, Principles for Federal Engagement in Standards Activities to Address National Priorities, Office of SCI. TECH. \& Pol., at 3 (Jan 17, 2012), available at http://www.whitehouse.gov/sites/default/files/omb/memoranda/2012/m-12-08_1.pdf ("Agencies considering a convening or active engagement role in private sector standards developing organizations in order to address a national priority area should state their reasons plainly [including why private sector leadership alone is insufficient].”).

${ }^{224}$ See A. Michael Froomkin, Wrong Turn in Cyberspace: Using ICANN to Route Around the APA and the Constitution, 50 Duke L.J. 17, 170 (2000).

${ }^{225}$ See, e.g., id.; Boswell and Cargas, supra note 183, at 158-63 (noting that the creation of the NAESB was a "subdelegation" of this sort that would pass Constitutional muster, discussing relevant cases and noting that FERC did not delegate regulatory authority to the NAESB).

${ }^{226}$ See, e.g., Amy J. Wildermuth, The Next Step: The Integration of Energy Law and Environmental Law, 31 Utah Envtl. L. Rev. 369, 382 (2011). The EISA is one of the omnibus energy acts in which Congress periodically reacts to a panoply of contemporary issues, leading to a fragmented body of energy law with "lots of pieces but no overall picture." Its many provisions 
statement that it is the "policy of the United States to support the modernization of the Nation's electricity transmission and distribution system." 227 The statute enumerated the over ten objectives described above. It created a Smart Grid Advisory Committee and Smart Grid Task Force to advise the DOE, and gave the DOE the responsibility to establish a Smart Grid Investment Matching Grant Program for qualifying projects. ${ }^{228}$

EISA Section 1305 gave NIST "primary responsibility to coordinate the development of a framework that includes protocols and model standards for information management to achieve interoperability of smart grid devices and systems." 229 This section directed NIST to seek input and collaborate with FERC, the new Smart Grid entities, SDOs (including IEEE and the National Electrical Manufacturers Association), NERC, and the GridWise Architecture Council. ${ }^{230}$ NIST was directed to create flexible, uniform, and technology neutral standards and enable traditional resources, distributed resources, renewables, storage, efficiency, and demand response to contribute to an efficient, reliable grid. ${ }^{231}$

Congress intended that FERC take an active review role, ${ }^{232}$ given its expertise and statutory mandates to regulate the grid. Once FERC finds that NIST has developed a "sufficient consensus" on standards, it must institute a rulemaking proceeding to "adopt" standards it deems necessary "to insure smart-grid functionality and interoperability in the interstate transmission of electric power, and regional and wholesale electricity markets."233 "Sufficient consensus" is therefore a threshold determination. ${ }^{234}$ Critically, the EISA did not give FERC any new powers to enforce any standards it might adopt, beyond its existing FPA authorities to regulate interstate transmission of electricity. Its role is limited to ensuring the standards' functionality.

Congress created this two-step process because both agencies have expertise, but neither could handle the task alone. NIST has no regulatory role, and as the grid's regulator, FERC would benefit from NIST's technical expertise. ${ }^{235}$ It was apparent that this would be an ongoing relationship, as hundreds of stan-

encourage fossil fuel development, renewable energy, and energy efficiency. Fred Sissine, Cong. Research Serv., Energy Independence and Security Act of 2007: A Summary of MAJor Provisions (2007), available at http://www.seco.noaa.gov/Energy/2007_Dec_21_Summary_Security_Act_2007.pdf.

${ }_{227} 42$ U.S.C.A. \$ 17381 (West 2012).

22842 U.S.C.A. \$ 17386 (West 2012).

22942 U.S.C.A. \$ 17385(a) (West 2012).

${ }^{230} 42$ U.S.C.A. $\$ \$ 17385(a)(1)-(2)$.

${ }^{231}$ See 42 U.S.C.A. $\$ 17385($ b).

232 Joseph P. Tomain, Fourth Annual Conference on Competition and Regulation in Network Industries: Smart Grid Innovation: Policy, Politics, and Law 9 (2011), available at www.crninet.com/2011/d14c.pdf. NIST does not have expertise in keeping the electric grid running. FERC does. It and it alone can evaluate "problems concerning cybersecurity, changes associated with our nation's generation mix including reliance on intermittent renewable resources, and problems that may arise with the development of electric and hybrid vehicles." Id.

${ }^{233} 42$ U.S.C.A. $\$ 17385(\mathrm{~d})$.

${ }^{234}$ FERC, supra note 205 , at slide 7 ("[Consensus] is really the first threshold determination that this Commission needs to make under the statute.").

${ }^{235}$ Werbach, supra note 11 , at 202. 
dards would not be set overnight. Time, of course, was of the essence. The ARRA's enactment in 2009 lent a sense of urgency to the standards development effort and put pressure on the two agencies to define the contours of their relationship quickly.

Some standards were needed sooner than others. ${ }^{236}$ The first source of priorities was the FERC "Smart Grid Policy Statement," a comprehensive primer that (among other things) set forth FERC's position on near-term standards development. ${ }^{237}$ FERC recommended a focus on key functions (wide-area situational awareness, demand response and consumer energy efficiency, energy storage, and electric transportation), cybersecurity, and network communications. ${ }^{238}$ NIST accepted these priorities and added two of its own: advanced metering and distribution grid management. ${ }^{239}$

NIST devised a three-phase plan to "rapidly identify an initial set of standards, while providing a robust process for continued development and implementation of standards as needs and opportunities arise and as technology advances." 240 This began with a public outreach effort to "identify applicable standards and requirements, gaps in currently available standards, and priorities for additional standardization activities." ${ }^{241}$ In an extraordinary undertaking perhaps unprecedented in the history of standards development, it held three public workshops in 2009, involving more than 1,500 participants and hundreds of organizations. ${ }^{242}$

Utility participants were a minority of those in attendance, and one observer wondered if being "severely underrepresented as the process moves to the various standards development organizations" would leave utilities with "little say over the final standards as they are developed without [their] significant input." 243 That theme would recur later.

NIST's contractor's report called for a "Smart Grid Panel and governance process to identify and guide the development of smart grid standards." 244 In

${ }^{236}$ NIST FRAMEWORK 2.0, supra note 5, at 22.

${ }^{237}$ Frisby, Jr. \& Trotta, supra note 73 , at 309 . One paragraph of the Smart Grid Policy Statement deserves special mention. FERC interpreted the EISA term "adopt" to give it "the authority to adopt a standard that will be applicable to all electric power facilities and devices with smart grid features, including those at the local distribution level and those used directly by retail customers so long as the standard is necessary for the purpose" of the EISA. FERC SMART GRID Policy, supra note 23, II 22. FERC claimed that EISA section 1305(d) does not exclude facilities used in local distribution or otherwise limit FERC authority to approve standards. State PUCs subsequently interpreted that statement as throwing down the jurisdictional gauntlet, viewing it as unwarranted interference with their authority to implement standards in their approval proceedings for distribution-level projects. See infra notes 321-346 and accompanying text.

${ }^{238}$ FERC SMART GRID POLICY, supra note 23, II 29.

${ }^{239}$ NIST FRAMEWORK 1.0, supra note 1 , at 8.

${ }^{240}$ NIST FRAMEWORK 2.0, supra note 5, at 15.

${ }^{241} I d$.

${ }^{242}$ See, e.g., Third Smart Grid Interoperability Standards Interim Roadmap Public Workshop, 74 Fed. Reg. 36,672 (July 24, 2009) (notice of Washington, DC workshop).

${ }^{243}$ David Owens, Time to Speak Up! Get Involved Developing Smart Grid Standards, IEEE Power \& Energy MAg. 87 (Mar.-Apr. 2010) available at http://www.iee.org/portal/cms_docs_ pes/pes/subpages/bullseye-folder/March10/March-IMV.pdf.

${ }^{244}$ EPRI NIST REPORT, supra note 156, at 19. 
November 2009, NIST created the Smart Grid Interoperability Panel ("SGIP") to serve this function. The SGIP does not directly develop or write standards, ${ }^{245}$ but instead participates in and coordinates their development. ${ }^{246}$ It has nearly 2000 members representing over 780 organizations. ${ }^{247}$ Its structure consists of a 25-member Governing Board (which sets priorities for the SGIP's work), Program Management Office, standing committees, "domain expert working groups" ("DEWGs") that provide expert technical advice, ${ }^{248}$ and "Priority Action Plans" ("PAPs"). ${ }^{249}$ The SGIP Governing Board strives for balance, with elected representatives from all twenty-two stakeholder categories. ${ }^{250}$ As NIST Administrator Arnold puts it, the fact that many stakeholders object to this demonstrates that the Board is balanced. ${ }^{251}$ Reflecting the importance of cybersecurity, the SGIP "has established one permanent working group, the Cybersecurity Working Group ("CSWG”),"252 charged with reviewing standards to determine whether they meet appropriate security requirements. Unanimity of members is not required to approve a standard. Approval consists of two steps:

${ }^{245}$ SGIP, SGIPGB AND SGIP CHARTER 3 (2012) [hereinafter SGIP BYLAwS AND CHARTER] (on file with the Harvard Law School Library). The SGIP is structurally similar to the Healthcare Information Technology Standards Panel. Id. at iii; see also Baird, supra note 166, at 73-75 (describing this panel and declaring it an important and necessary departure from private standardsetting).

${ }^{246}$ Introduction to the NIST Smart Grid Collaboration Wiki, NIST SGIP, http://collaborate. nist.gov/twiki-sggrid/bin/view/SmartGrid/SGIPAbout (last visited Jan. 22, 2013) (on file with the Harvard Law School Library).

${ }^{247}$ Welcome to the NIST Smart Grid Collaboration Wiki, What is the Smart Grid Interoperability Panel?, NIST SGIP, http://collaborate.nist.gov/twiki-sggrid/bin/view/SmartGrid/Web Home\#What_is_the_Smart_Grid_Interoper (last visited Jan. 22, 2013) (on file with the Harvard Law School Library). Another organization that provides input to NIST is the Smart Grid Federal Advisory Committee, begun in September 2010, that consists of 15 experts from industry, academia, and trade associations. NIST Smart Grid Advisory Committee, NIST, http://www.nist. gov/smartgrid/committee.cfm (last visited Jan. 22, 2012) (on file with the Harvard Law School Library).

${ }^{248}$ NIST Framework 1.0, supra note 1, at 16, 160; Domain Expert Working Groups, Gridwise Architecture Council, http://www.gridwiseac.org/about/dewg.aspx (last visited Jan. 22, 2013) (on file with the Harvard Law School Library) (discussing formation of DEWGs in conjunction with the GridWise Architecture Council); CARvallo \& Cooper, supra note 2, at 163. Current DEWGs include Transmission and Distribution, Home-to-Grid, Building-to-Grid, Industry-to-Grid, PEV-to-Grid, Business and Policy, and Distributed Renewables, Generation and Storage. Domain Expert Working Groups (Analysis), Current DEWGs within the SSGP, NIST SGIP, http://collaborate.nist.gov/twiki-sggrid/bin/view/SmartGrid/DEWGs (last visited Jan. 22, 2013) (on file with the Harvard Law School Library).

${ }^{249}$ NIST FRAMEWORK 2.0, supra note 5, at 136, 160.

${ }^{250}$ SGIP Bylaws AND CharTer, supra note 245, at 5-6; NIST Smart Grid Collaboration Wiki, SGIP Leadership, NIST SGIP, http://collaborate.nist.gov/twiki-sggrid/bin/view/SmartGrid/ WebHome\#SGIP_Leadership (last visited Jan. 22, 2013) (on file with the Harvard Law School Library).

${ }^{251}$ FERC Technical Conference 2011, supra note 10 (statement of George Arnold), at 12 (noting that utilities claim they are underrepresented while others claim the Board "is dominated by the utilities," so "[t]his is probably an indication that we have struck a reasonable balance").

${ }^{252}$ NIST FRAMEWORK 2.0, supra note 5, at 130. 
a Governing Board recommendation and a vote by the SGIP members, with both votes requiring $75 \%$ in favor of approval. ${ }^{253}$

\section{Figure 3: SGIP Technical Activities 254}

\begin{tabular}{|c|c|c|}
\hline $\begin{array}{l}\text { Name of Committee or } \\
\text { Working Group }\end{array}$ & Purpose or Mandate & Notes \\
\hline $\begin{array}{l}\text { Smart Grid Architecture } \\
\text { Committee ("SGAC") }\end{array}$ & $\begin{array}{l}\text { Maintains a conceptual } \\
\text { reference model for the } \\
\text { Smart Grid; develops high- } \\
\text { level architectural principles } \\
\text { and requirements }\end{array}$ & \\
\hline $\begin{array}{l}\text { Smart Grid Testing and } \\
\text { Certification Committee } \\
\text { ("SGTCC") }\end{array}$ & $\begin{array}{l}\text { Creates and maintains a } \\
\text { framework for compliance, } \\
\text { interoperability and } \\
\text { cybersecurity testing and } \\
\text { certification for } \\
\text { recommended Smart Grid } \\
\text { standards. }\end{array}$ & \\
\hline $\begin{array}{l}\text { Cyber Security Working } \\
\text { Group ("CSWG") }\end{array}$ & $\begin{array}{l}\text { Identifies and analyzes } \\
\text { security requirements and } \\
\text { develops a risk mitigation } \\
\text { strategy to ensure the } \\
\text { security and integrity of the } \\
\text { Smart Grid. }\end{array}$ & \\
\hline $\begin{array}{l}\text { Priority Action Plans } \\
\text { ("PAPs") }\end{array}$ & $\begin{array}{l}\text { Addresses specific } \\
\text { standards-related gaps and } \\
\text { issues for which resolution is } \\
\text { most urgently needed. }\end{array}$ & $\begin{array}{l}\text { Currently totaling } 16 \text { PAPs; } \\
\text { more will be added as } \\
\text { necessary. }\end{array}$ \\
\hline $\begin{array}{l}\text { Domain Expert Working } \\
\text { Groups ("DEWGs") }\end{array}$ & $\begin{array}{l}\text { Perform analyses and } \\
\text { provide expertise in specific } \\
\text { application domains. }\end{array}$ & $\begin{array}{l}\text { Seven current DEWGs are: } \\
\text { Transmission and } \\
\text { Distribution; Building to } \\
\text { Grid; Industry to Grid; } \\
\text { Home to Grid; Business and } \\
\text { Policy; Vehicle to Grid; } \\
\text { Distributed Renewables, } \\
\text { Generation, and Storage }\end{array}$ \\
\hline
\end{tabular}

A "PAP" is NIST's term for a focused SGIP effort to "coordinate . . . resolving urgent standards issues." 255 The SGIP PAP leadership team identifies a standards organization to lead the effort and produce a standard, which must

${ }^{253}$ SGIP BYLAwS AND CHARTER, supra note 245, at 23 ("Seventy-five percent $(75 \%)$ of the quorum must approve a technical measure for it to pass."); SGIP STANDARds Catalog, supra note 147, at 5 (requiring $75 \%$ votes of both to approve a standard for the Catalog of Standards).

${ }^{254}$ Welcome to the NIST Smart Grid Collaboration Wiki, SGIP Site, NIST SGIP, http:// collaborate.nist.gov/twiki-sggrid/bin/view/SmartGrid/WebHome (last visited Jan. 22, 2013) (on file with the Harvard Law School Library).

${ }^{255}$ NIST FRAMEWORK 2.0, supra note 5, at 64. 
then go through the approval process. Any organization assuming this responsibility must have a "robust consensus process" meeting the principles of OMB Circular A119 and the NTTAA. ${ }^{256}$ SGIP works to "facilitate this process, ensure that all PAP materials are publicly available to the extent possible as they are developed on the NIST Smart Grid Collaboration Site, and provide guidance as needed when significant differences among the participants in the PAP occur, or there is uncertainty about the PAP goals." ${ }^{257}$ In the spirit of openness and transparency, each PAP has a collaborative wiki page to engage stakeholders. ${ }^{258}$

In 2010, after its preparatory efforts, NIST issued a "Framework and Roadmap for Smart Grid Interoperability Standards, Release 1.0" ("Framework"). ${ }^{259}$ The Framework identified seventy-five existing standards applicable (or likely to be applicable) to the Smart Grid. Of these, twenty-five were identified as having "strong stakeholder consensus," even though they might require modifications or further development, and the rest were marked "for further review."260 An example of the first group is the ZigBee Alliance's "Smart Energy Profile" 2.0 ("SEP 2.0") specification for home area network communications. ${ }^{261}$

There was, and is, much work to be done. The Framework specified 15 high-priority gaps, harmonization issues (in addition to cybersecurity) and PAPs to address important near-term concerns. ${ }^{262}$ It described a high-level "conceptual reference model" for the Smart Grid that is "meant to foster understanding of Smart Grid operational intricacies but not meant to prescribe how a particular stakeholder will implement the Smart Grid." The NIST conceptual model maps the Smart Grid's "system of systems,"263 identifying "do-

${ }^{256}$ Opening remarks to FERC Technical Conference 2011, supra note 10, at 6 .

${ }^{257}$ NIST FRAMEWORK 2.0, supra note 5, at 64.

${ }^{258}$ For example, NIST's website for PAP10, "Standard Energy Usage Information," details the extensive work that went into the development of the standard, with numerous webinars and open meetings, and outreach activities to other standards organizations. NIST Smart Grid Collaboration Wiki, PAP10: Standard Energy Usage Information, NIST SGIP, http://collaborate.nist. gov/twiki-sggrid/bin/view/SmartGrid/PAP10EnergyUsagetoEMS (last visited Jan. 22, 2013) (on file with the Harvard Law School Library); see infra notes 269-285 and accompanying text.

${ }^{259}$ See generally NIST FRAMEWORK 1.0, supra note 1.

${ }^{260} I d$. at 61 . The list of standards is set forth at pages $50-60$.

${ }^{261} \mathrm{Id}$. at 7. The Smart Energy Profile specification was listed in the set of twenty-five Framework standards. See id. at 57. This specification provides a set of functionality for home area networks designed to meet the requirements established in the OpenHAN specification of the Utility Communications Architecture International Users Group, which itself was included as a Framework standard. See UCA Int'L Users GrP., Utility AMI 2008 Home Area Network SySTEM REQUiREMENTS SPECIFICATION (2008), available at http://osgug.ucaiug.org/sgstore/ Shared\%20Documents/UtilityAMI\%20HAN\%20SRS\%20-\%20v1.04\%20-\%20080819-1.pdf;

NIST FrAMEWORK 1.0, supra note 1, at 57-58; see also SGIP, PAP 18: SEP 1.x to SEP 2.0 Transition and Coexistence Guidelines and Best Practices (2011) (detailing how utilities that installed smart meters meeting earlier versions of SEP can transition to version 2.0 when it is complete).

${ }^{262}$ NIST FRAMEWORK 1.0, supra note 1, at 7.

${ }^{263}$ IEEE: The Expertise to Make Smart Grid a Reality, IEEE SMART GRID, http://smartgrid. ieee.org/ieee-smart-grid/smart-grid-conceptual-model (last visited Jan. 22, 2013) (on file with the Harvard Law School Library). 
mains" (for example, the "Customer" domain) and potential paths of information flow among them, but not specifying how interactions take place. ${ }^{264}$ The Framework also described the strategy to help ensure Smart Grid cybersecurity. An updated version 2.0 of the Framework was released for comment in late 2011.

In July 2011, NIST added six standards to a new "Catalog of Standards" ("Catalog"), 265 a major new toolkit for all Smart Grid stakeholders. The Cata$\log$ is a "compendium of standards and practices considered to be relevant for the development and deployment of a robust and interoperable Smart Grid." It is not "a "cookbook' to ensure interoperability," but a list of "specifications that have significant import to enabling the Smart Grid and enhancing its capabilities." 266 The criteria for a standard's listing in the Catalog include "Community Acceptance," in which the standard is "widely acknowledged as facilitating interoperability related to the integration of devices or systems that enable Smart Grid capabilities."267

In the third phase of its plan, NIST is developing and implementing a framework for testing and certification of how standards are implemented in Smart Grid devices, systems, and processes. This is essential to ensure interoperability and security under real world conditions. In 2012, NIST issued the second version of the document explaining this process, the Interoperability Process Reference Manual. ${ }^{268}$

\section{The SGIP in Operation: PAP10 (Standard Energy Usage Information)}

One of the SGIP's first and most important priorities was PAP10, "Standard Energy Usage Information."269 PAP10 activities focused on an "Energy Usage Information" ("EUI") data model. As the name suggests, this model was intended to define and standardize energy usage information throughout the Smart Grid, with the goal of making information more readily available to consumers and third parties. This standard is extremely important, ${ }^{270}$ specifying

${ }^{264}$ NIST FRAMEWORK 1.0, supra note 1, at 32-36.

${ }^{265}$ SGIP Catalog of Standards, NIST SGIP, http://collaborate.nist.gov/twiki-sggrid/bin/view/ SmartGrid/SGIPCatalogOfStandards (last visited Jan. 22, 2013) (on file with the Harvard Law School Library). The process for adding standards to the Catalog was completed in May 2011. NIST FRAMEWORK 2.0, supra note 5, at 65 . This was after the initial submission of standards to FERC, and therefore led to criticism that those standards had not completed the full SGIP process life cycle. See infra notes 295-298 and accompanying text.

${ }^{266}$ SGIP Standards Catalog, supra note 147, at 2.

267 Id. at 5.

${ }^{268}$ Updated Guidelines to Help Ensure Electrical Devices are Smart Grid Ready, NIST ENG'G LAB. (Jan. 24, 2012), http://www.nist.gov/el/smartgrid-012412.cfm. The IPRM may be found at Smart Grid Testing \& Certification Committee (SGTCC), NIST SGIP, Jan., 2012, https:// collaborate.nist.gov/twiki-sggrid/pub/SmartGrid/SmartGridTestingAndCertificationCommittee/ IPRM_final_-_011612.pdf.

${ }^{269}$ NIST FRAMEWORK 1.0, supra note 1, at 79. The PAP10 Standard Energy Usage Information website is located at NIST SGIP, supra note 258.

${ }^{270}$ See, e.g., GridWise Architecture Council, supra note 8, at 30 (discussing the importance of data models to "bridge between different communities"). 
the "vocabulary that will be used by devices and services" across the Smart Grid's domains. ${ }^{271}$ California and Texas had already required their consumers to have electronic access to energy usage data. ${ }^{272}$ Prompt development of a standard was essential to this and other functions: facilitating DR, consumer participation in energy markets, and connecting electric vehicles and DG to the grid, among others. ${ }^{273}$

The EUI was not meant to standardize the means for exchanging data, but instead to create a "seed" - a core set of information that could be made available to consumers or authorized third parties. Subsequent standards would use this foundation to address specific uses. ${ }^{274}$ The need for this type of information model was compelling. Without a standard that defined key terms, every interaction across the Smart Grid would have to redefine them anew. ${ }^{275}$

In 2010, the SGIP Governing Board requested that the PAP10 leadership team expedite the production of an information model standard "by a recognized Standards Developing Organization" meeting NTTAA requirements. ${ }^{276}$ NIST selected the NAESB for this purpose, with a parallel effort by the American Society of Heating, Refrigerating and Air-Conditioning Engineers ("ASHRAE") to settle on facility energy information models. By the normal standards clock, this was a quick turnaround.

Development continued throughout 2010, culminating in the production of the NAESB EUI standard in December 2010. ${ }^{277}$ A CSWG review found that the EUI did not present cybersecurity problems by itself because it "does not present requirements for communication, storage, or access to energy usage information." ${ }^{278}$ By separate votes of the SGIP Governing Board and members

${ }^{271}$ Summaries of First Six Catalog of Standards Entries, NIST (July 26, 2011), http:// www.nist.gov/smartgrid/sgip-072611-factsheet.cfm.

272 See 2010 Cal. Stat. Ch. 497; Cal. Pub. Util. Comm'n, Draft Decision Adopting Rules to Protect The Privacy and Security of the Electricity Usage Data of the Customers of Pacific Gas and Electric Company, Southern California Edison Company, and San Diego Gas \& Electric Company, R.8-12-009 (2008), available at http://docs.cpuc.ca.gov/efile/ $\mathrm{PD} / 134875$.pdf (implementing the statutory mandate and establishing privacy and security provisions for data).

${ }^{273}$ NIST SGIP, supra note 258.

${ }^{274}$ SGIP, REPORT TO THE SGIP GOVERNING BOARD: PAP10 PLAN 2 (2010), available at http:/ /www.naesb.org/pdf4/smart_grid_pap10_062210w6.pdf [hereinafter SGIP PAP10 2010 PLAN] ("PAP10 will not cover all interactions associated with energy in the home or commercial space. Additional standard information models will be necessary to support load management, for example. Additionally, the proposed standard will be limited to defining an information model only. The implementation of messaging using the model and the syntax by which messaging is encoded is left to SDOs and Standards Setting Organizations that will use the 'seed' standard.").

${ }^{275}$ NIST SGIP, supra note 258 (noting that "[i]n the absence of these standards, software developers and utilities would have to negotiate pair-wise interfaces, an impractical situation").

276 SGIP PAP10 2010 PLAN, supra note 274, at 1.

277 The NAESB EUI model is described in detail in NAESB, NAESB ENERGY UsAGE INFORMATION MODEL (2010), available at http://www.naesb.org/pdf4/naesb_energy_usage_information_model.pdf.

${ }^{278}$ See NIST Smart Grid Collaboration Wiki, SGIP CoS: NAESB PAP10 Energy Usage Information, NIST SGIP, http://collaborate.nist.gov/twiki-sggrid/bin/view/SmartGrid/SGIPCosSIFNAESBREQ18WEQ19 (last visited Jan. 22, 2013) (on file with the Harvard Law School Library). 
(in January and June 2011, respectively), the standard was approved and added to the Catalog of Standards. ${ }^{279}$

Among the most anticipated extensions of the EUI was the actual exchange mechanism for customer access to energy usage information. "The NAESB Energy Services Provider Interface" ("ESPI") standard, designed to provide a standardized process and interface for this purpose, became official at the end of 2011.280 The standard "defines a consistent method for the authorization of third party access to retail consumer's usage information and a standardized interface for the exchange of that information." 281

An excellent example of how the combination of the EUI and ESPI are already being used in the Smart Grid is the "Green Button Initiative," announced by U.S. Chief Technology Officer Aneesh Chopra in January 2012 as an effort to give consumers "standard, routine, easy-to-understand access to their own energy usage data." 282 California's three major investor-owned utilities (PG\&E, SDG\&E, and Southern California Edison) promoted the Green Button idea. ${ }^{283}$ Their websites are based on the NAESB standards. They allow consumers to download their energy usage information in a straightforward, standardized format, and share it (if they so choose) with authorized third parties. ${ }^{284}$

This is as revolutionary in its significance as the Internet's first uses, for it hints at the potential for much more robust uses of the data. ${ }^{285}$

\section{FERC's Order and Its Implications for Smart Grid Development AND ENERGy LAW Federalism}

In 2010, NIST requested that FERC put a stamp of approval on a handful of standards, a small fraction of those identified in the Framework. However,

${ }^{279}$ See NIST FRAMEWORK 2.0, supra note 5, at 83; NIST SGIP, supra note 278; Press Release, Smart Grid Panel Approves Six Standards for Catalog, NIST, http://www.nist.gov/smartgrid/sgip-072611.cfm (John McDonald, SGIP Governing Board Chair, commenting that "[t]he energy usage information standard may very well be the most interesting to consumers at this point").

${ }^{280}$ Press Release, NAESB, NAESB Announces Launch of ESPI Web Site to Support the Green Button Initiative (Jan. 25, 2012), http://www.naesb.org/pdf4/012512press_release.pdf.

${ }^{281} I d$.

${ }^{282}$ See, e.g., Green Button: Providing Consumers with Access to Their Energy Data, DOE (Jan. 19, 2012), http://energy.gov/articles/green-button-providing-consumers-access-their-energydata; Introducing Green Button, NIST (Jan. 20, 2012), available at http://www.nist.gov/smartgrid/ upload/1-20-12_Green_Button_Webinar_-_Wollman_and_Irwin.pdf; Jeff St. John, How Federal Legislation Could Change Digital Energy Data, GiGaom (June 1, 2011), http://gigaom.com/cleantech/how-federal-legislation-could-change-digital-energy-data/.

${ }^{283}$ Standards Gurus Propose Way to Get More Uutilities on Board with SGIP, SMART GRID TODAy ( Nov. 23, 2011), http://www.smartgridtoday.com/public/3488print.cfm.

${ }^{284}$ Green Button, PGE, http://www.pge.com/greenbutton/ (last visited Jan. 22, 2013) (on file with the Harvard Law School Library).

${ }^{285}$ Mike Orcutt, The Energy Use of New York City's Buildings, Visualized, TECH. ReVIEw (Feb. 13, 2012) http://www.technologyreview.com/blog/energy/27550/?nlid=nldly\&nld=201202-14 (discussing the use of a model for energy consumption in New York that could be improved with better data). 
the significance of the request extended far beyond the standards' technical merits. The discussion over whether FERC should "adopt" the standards became a high-stakes test of the Smart Grid's future and the process by which it will be developed. Utilities, vendors, PUCs, and others debated major themes, including how stakeholders should govern the standard-setting process (and, by extension, have authority over the Smart Grid going forward) and how federal and state actors will interact with each other. These issues dominated a lengthy public discussion.

The request itself involved five families of standards developed by the International Electrotechnical Commission ("IEC"), ${ }^{286}$ one of three organizations that set international standards for electric and electronic technologies. The IEC standards are "extremely detailed, highly prescriptive technical specifications, down to the point of directing which bytes go where in electronic packets on the wire." 287 As industry standards go, they are a no-brainer. NIST Administrator Arnold noted later that major IOUs rely on them in their existing systems, quoting a utility executive's statement that the "five IEC standards are among the most mature in the industry." 288

Criticisms voiced to FERC ranged from fine-grained observations about the SGIP process to broad concerns about FERC's role and its implications for the federal-state relationship in electric utility regulation. After receiving the standards, FERC solicited considerable input from Smart Grid stakeholders in two technical conferences and a rulemaking docket. Nearly all commenters opposed FERC adoption. However, most commenters praised the SGIP's work. 289

FERC's response addressed both viewpoints, and in doing so supported the democratic NIST-led process for standards development, turning federalism from a hindrance for Smart Grid development into a positive framework for implementation. Its order stated that the standards did not have "sufficient consensus," so it would not proceed with a rulemaking proceeding to "adopt" those standards as mandatory FERC regulations. ${ }^{290}$ This sounds like rejection,

${ }^{286}$ Welcome to the IEC, IEC, http://www.iec.ch/about/, (last visited Jan. 22, 2013) (on file with the Harvard Law School Library).

${ }^{287}$ FERC Technical Conference 2011, supra note 10 (statement of Ron Highfill), at 29. As an example, the IEC 61970 standards "define application-level energy management system interfaces and messaging for distribution grid management in the utility space." NIST FRAMEWORK 1.0, supra note 1, at 54; Int'l Electrotech-NICAL Comm'N, Summary of Use, Application, Cybersecurity, and Functionality of Smart Grid InTERoperability Standardis Identified BY NIST 1 (2010), available at www.smartgridlegalnews.com/5_standards.pdf (discussing the standards in depth). An ongoing activity of NIST's PAP10 is work to establish the relationship of the NAESB EUI standard with this family of standards. NIST SGIP, supra note 258.

${ }^{288}$ Opening Remarks to FERC Technical Conference 2011, supra note 10, at 5.

289 Before the Department of Energy, In the Matter of Addressing Policy and Logistical Challenges to Smart Grid Implementation, Dep't of Energy Third Request for Info. On Smart Grid Issues (comments of AT\&T, Inc.) (on file with the Harvard Law School Library) ("NIST working groups developing Smart Grid interoperability standards have been productive endeavors with excellent output that will foster innovation in connection with the Smart Grid.").

${ }^{290}$ Understanding the implications of FERC's decision not to adopt the standards requires some careful thought about two unclear terms in the EISA: the threshold inquiry of "sufficient 
but its benefits are readily apparent. For one, FERC's order demonstrates that regulatory agency rulemaking is not necessary in a legal framework for standards development. FERC recognized the SGIP as an appropriate and necessary forum, which is producing results and will continue to do so. Noticing that, without making a separate judgment about "sufficient consensus," allowed the SGIP process to continue without superimposing the additional layer of review of a rulemaking proceeding. This decision also let states act first in adopting the NIST standards, rather than triggering their resentment of federal energy regulations they perceive as intruding on their authority (and potential litigation).

\section{A. Blessing the Process}

Although FERC does not develop interoperability standards, its role as an energy regulator and standards adopter via the EISA makes its view critical. The EISA allows FERC to make judgments about NIST's efforts "[a]t any time." ${ }^{291}$ This envisions periodic submissions, ${ }^{292}$ but provides no guidance about how FERC should decide when and whether "the Institute's work" has "led to sufficient consensus in the Commission's judgment."293 This gives FERC significant leeway in interpreting the effectiveness of the NIST-led process. $^{294}$

\section{Criticisms of the Process}

There were a number of criticisms of the SGIP. Some focused on the SGIP's due process attributes. Commenters believed "consensus" meant that Smart Grid stakeholders must agree that NIST has properly identified standards for submission. ${ }^{295}$ They criticized the initial submission's hasty timing and

consensus" and FERC's responsibility to "adopt" standards. NIST's transmittal to FERC was a brief letter naming the standards and describing their role in the Smart Grid. NIST, NIST SMART Grid Advisory CommitTeE (SGAC) Report 28 (2012) [hereinafter NIST SGAC RePort] available at www.nist.gov/smartgrid/upload/NIST_SGAC_Final_Recommendations_Report_3-05-12_ with_Attachments.pdf. That left others free to interpret the statute as they saw fit.

29142 U.S.C.A. § 17385(d) (West 2012).

${ }^{292}$ FERC, supra note 205, at slide 5 (FERC staff proposing to conduct periodic rulemakings).

${ }^{293} \mathrm{Id}$. at 7 . FERC staff had recommended "that the Commission generally rely on the National Technology Transfer and Advancement Act (NTTAA) as guidance in determining sufficient consensus, along with comments received in the rulemaking proceeding."

${ }^{294}$ See, e.g., Chris King, FERC Says "Consensus" Lacking for Smart Grid Standards: What Consensus?, SMART GRID WATch (July 27, 2011), http://www.emeter.com/smart-grid-watch/ 2011/ferc-says-consensus-lacking-for-smart-grid-standards-what-consensus/ (noting that Enernex chairman and CTO Erich W. Gunther observed that while FERC did not define "sufficient consensus," it could mean five different things); see also Frisby, Jr. \& Trotta, supra note 73, at 313-14.

${ }^{295}$ Before the Federal Energy Regulatory Commission, Smart Grid Interoperability Standards, Docket No. RM11-2-000 8 (comments of the Midwest Independent Transmission System Operators, Inc.), available at https://www.midwestiso.org/Library/Repository/Tariff/FERC\%20 Filings/2011-04-22\%20Docket\%20No.\%20RM11-2-000.pdf (calling for FERC to "independently determine whether there is sufficient consensus that the NIST process created appropriate standards"). 
form. ${ }^{296}$ One commenter argued NIST did not have a "formal and transparent process so that there is broad, documented industry consensus as to exactly when and which standards will be provided to the Commission." ${ }^{297}$ Others pointed out (correctly) that NIST had submitted the first batch of standards before it had its full suite of procedures in place to add standards to the Catalog. 298

Utilities' most persistent arguments are claims of underrepresentation in the SGIP process. One utility executive argued there was no "sufficient consensus" because standards are not "subject to review and vote by the entire SGIP pursuant to a balanced voting process before being placed in the SGIP's Catalog of Standards."299 Utilities object to the SGIP's supermajority voting requirement, believing they should have a larger voice in standard-setting to reflect their significant investments in the Smart Grid. They make up about $10 \%$ of SGIP members, so the SGIP could therefore vote to approve a standard over the objection of every utility member. ${ }^{300}$

${ }^{296}$ FERC Technical Conference 2011, supra note 10 (statement of John Lucas), at 36 (noting that "the current pace and the broad scope of the process is in our view inconsistent with establishing true and informed industry consensus, as you would find in the NERC process for setting a standard or the NAESB process for establishing a business practice standard").

${ }^{297}$ Smart Grid Interoperability Standards: United States of America Before the Federal Energy Regulatory Commission, Docket No. RM-11-2-000 2 (2011) (comments of John A. Lucas, Southern Company Services, Inc.), available at http://www.ferc.gov/eventcalendar/Files/2011013 1084230-Lucas,\%20Southern.pdf [hereinafter "Lucas Docket Comments"] (adding that "I must admit Southern is among those who were not aware that these standards would be the first standards provided to the Commission by NIST"). Another commenter observed that sending standards five at a time would lead to piecemeal development and give inadequate guidance to the states. FERC Technical Conference 2011, supra note 10 (statement of Gib Sorebo), at 54.

John Lucas also believed that the standards had not achieved consensus because utilities are underrepresented in the IEC. Lucas Docket Comments, at 2 (noting that "regulated electric utilities have had limited involvement in the IEC process for the referenced five families of standards"). Utilities do not have votes in the IEC process, but it is one of the "well-recognized, international standards bodies" that follow the essential principles for standards development. Introduction to AWSI, AM. NAT'L STANDARDS InST., http://www.ansi.org/about_ansi/introduction/ introduction.aspx (last visited Jan. 22, 2013) (on file with the Harvard Law School Library) (noting that "[a]11 ANSI-accredited standards developers follow the Essential Requirements which embrace globally-accepted principles of standardization implemented by well-recognized, international standards bodies such as the ... IEC [International Electrotechnical Commission]"); see INT'L EleCtroteCh-NICAL. Comm'N, supra note 287, at 9 (comments by IEC on cybersecurity review of its standards, noting that "IEC meets the requirements of NTTAA as a voluntary consensus standards development organization").

${ }^{298}$ FERC Standards Order, supra note 16, If 7 (noting that "certain aspects of the current NIST process were not in place during development of the NIST Framework document and identification of the IEC standards").

${ }^{299}$ FERC Technical Conference 2011, supra note 10 (statement of John Lucas), at 38 (emphasis added).

${ }^{300}$ NIST SGAC REPORT, supra note 290 , at 31 (noting that " $100 \%$ of the utility companies could vote against some issue in the SGIP, but it could still carry the day because of the current majority voting procedures"). In practice, the approval level is much higher than the requisite $75 \%$. The first six standards added to the Catalog of Standards (including the NAESB EUI standard) were approved by $90 \%$ of the SGIP's members. Market News, Smart Grid Panel Approved First Six Standards, KLEANIndustries (Aug. 23, 2011), http://www.kleanindustries.com/s/environmental_market_Industry_news.asp?ReportID=475904. 
To remedy this, the commenter proposed a "super-majority of voting members [and] a level of support from all industry segments" to approve a standard. ${ }^{301}$ Some SDOs, including NAESB, require this. ${ }^{302}$ By definition, this invokes a much broader issue: how the process should protect the interests of other stakeholders, including future entrants. The SGIP supermajority voting requirement reflects the OMB/NTTAA principle that, "substantial agreement" is "general agreement, but not necessarily unanimity." 303 Granting utilities a greater say allows them to take part in the SGIP and then reject its outcome on the grounds that the process was not "balanced." 304 It should be weighed carefully against the OMB/NTTAA principle that no one stakeholder should dominate the process. ${ }^{305}$

Commenters also claimed that the standards were not ready because they would not promote reliability and were not cybersecure. While the CSWG had assessed the standards' cybersecurity, ${ }^{306}$ some argued that the NIST three-volume set of guidelines was "much more of a philosophical document than a handbook for achieving a secure operating environment." ${ }^{307}$ Numerous participants called for more rigorous review, and several called for development of a "security addendum" to address important issues. ${ }^{308}$ NIST also would need to coordinate with federal agencies, such as the Department of Homeland Security, with relevant expertise and jurisdiction. As for reliability, commenters called for formal reviews by industry participants in conjunction with NERC, which had not happened prior to the submission of the standards. ${ }^{309}$

${ }^{301}$ United States Before the Federal Energy Regulatory Commission, Smart Grid Interoperability Standards, Docket No. RM11-2-000 (comments of John Lucas), available at http://www. ferc.gov/eventcalendar/Files/20110131084230-Lucas,\%20Southern.pdf.

302 Certificate of Incorporation of the North American Energy Standards Board, INC. 6 (2008) available at http://www.naesb.org/pdf/naesb_certificate_112108.pdf (requiring a $67 \%$ supermajority and $40 \%$ approval within each market segment).

303 OMB Circular, supra note $189, \S 4(\mathrm{a})(1)(\mathrm{v})$; see also SGIP Bylaws AND Charter, supra note 245, at 3-4; NAT'L SCI. AND TECH. CounCIL, supra note 3, at 29; Werbach, supra note 11 , at 209 ("[C]onsensus" is "defined as general agreement, not necessarily unanimity."). This requires careful consideration of views, including "a process for attempting to resolve objections by interested parties, as long as all comments have been fairly considered, each objector is advised of the disposition of his or her objection(s) and the reasons why, and the consensus body members are given an opportunity to change their votes after reviewing the comments." OMB CIRCULAR, supra note 303, \& 4(a)(1)(v).

${ }^{304}$ FERC Technical Conference 2011, supra note 10 (statement of George Arnold), at 12.

305 OMB CIRCULAR, supra note 303, § 4(a)(1)(ii).

306 Opening Remarks to FERC Technical Conference 2011, supra note 10, at 5.

${ }^{307}$ NIST SGAC REPORT, supra note 290, at 29.

${ }^{308}$ See, e.g., FERC Technical Conference 2011, supra note 10 (statement of Michael Assante), at 79, 83 (noting that "an insufficient number of experts in cyber security, control system security, and utility operations were engaged in an informed manner throughout the review process" and that "direct necessary addendums . . . to address identified concerns and provide credible security guidance [should be provided] along with adoption or design implementation of the standards"); FERC Technical Conference 2011, supra note 10 (statement of Daniel Thanos), at 25 (commenting that the optimal cybersecurity solution was "the developing of an overriding security addendum that must be adopted along with the standards").

${ }^{309}$ NIST SGAC REPORT, supra note 290 , at 19 ("There is a gap in terms of reliability and implementation reviews within the SGIP . . . . There needs to be a formal review of these interoperability standards with respect to the reliability and implementation readiness by industry representatives who have the primary responsibility for safety, operation and reliability of the grid."). 


\section{FERC's Response}

FERC had to enable standards development to move forward, while addressing these complaints. However, the EISA language boxed FERC in. FERC had to decide whether the five families of standards had "sufficient consensus." If that consensus existed, FERC was required to commence a rulemaking proceeding and make a substantive judgment about the standards. Adopting the standards would incur the wrath of those objecting to a federal mandate. Rejecting them, for whatever reason, might cast doubt on the SGIP process. If FERC found there was no consensus, it might also impugn that process.

NIST itself suggested that FERC "could send appropriate signals to the marketplace by recommending use of the NIST Framework without mandating compliance with particular standards." 310 Simultaneously, FERC could value the SGIP's work by endorsing the SGIP process. In its order of July 2011, FERC therefore stated, "we find insufficient consensus to institute a rulemaking proceeding at this time to adopt the five families of standards." 311 It did not elaborate on what it meant by "consensus," except to observe that "[c]ommenters are nearly unanimous that we should not adopt these standards at this time, citing concerns with cyber security deficiencies and potential unintended consequences from premature adoption of individual standards." 312 It added an important paragraph, which stated: "We believe that the best vehicle for developing smart grid interoperability standards is the NIST interoperability framework process, including the work of the SGIP and its committees and working groups." 313

As an example, FERC could not have been clearer about how it expects cybersecurity to be addressed. In the order, it stated, "[s]takeholders concerned with smart grid cyber security should actively participate in the NIST interoperability framework process, including the SGIP Cyber Security Working Group." 314 As FERC noted, NIST has strengthened its reliability and cybersecurity review processes. ${ }^{315}$ FERC expects these processes to be the central forum for resolving these important issues.

It may be appropriate for FERC to review some standards to the extent they are necessary to ensure cybersecurity or reliability. ${ }^{316}$ However, FERC's order makes its review secondary to allowing the crowd of stakeholders to address and resolve important issues. This allows the SGIP flexibility to adapt to concerns about "sufficient consensus" more quickly than a regulatory process

${ }^{310}$ FERC Standards Order, supra note 16, II 9.

${ }^{311}$ Id. II 1.

${ }^{312}$ Id. II 7.

${ }^{313}$ Id. II 10.

${ }^{314}$ Id. II 12.

${ }^{315}$ Id. II 11.

316 See NAt'L Sci. And Tech. Council, supra note 3, at $29 \mathrm{n} .32$ ("We firmly believe that there will be appropriate reasons for FERC to mandate the use of specific standards in the future and EISA gives them the authority to make that call."). 
can. ${ }^{317}$ In some cases, the SGIP has made changes already (for example, developing the Catalog), ${ }^{318}$ and others are contemplated. This evolution is useful. The dynamic relationship between standards and Smart Grid architecture ${ }^{319}$ dictates that standard-setting itself should be an evolving process. Like standards themselves, the structure has to be flexible and accommodate change. By not interpreting "sufficient consensus," FERC recognized that stakeholders themselves can steer the SGIP's evolution, making process changes when they deem it necessary.

This has major significance for future Smart Grid governance. Smart Grid stakeholders, like those of the Internet, should have a strong stake in the network's future. If achieving "sufficient consensus" requires changes to the SGIP process, the appropriate remedy is not first and foremost for FERC to make those decisions, although FERC's position guarantees it will have influence if it chooses to use it. If utilities believe they are underrepresented in the SGIP process, they should make that argument to the full complement of Smart Grid stakeholders, not one central regulator. The open public process also makes capture of the SGIP process less likely than capture of a regulatory agency. ${ }^{320}$ However, if FERC notices that one actor has dominated the SGIP's process for setting a specific standard, it might step in to articulate that a consensus has not been reached.

\section{B. Treating Federalism as a Means for Implementation Instead of a Barrier}

In the technical conferences and rulemaking docket, the meaning of "adopt" was "the question everyone [had] in mind," ${ }^{21}$ and it became a lightning rod for a host of concerns about federalism and FERC's role in the standard-setting process.

\section{Concerns of Smart Grid Stakeholders}

A FERC staff member asked a technical conference panelist whether "there is a spectrum of 'adopt' where it really means 'not necessarily looking to adopt individual standards, but as I understood it, kind of blessing a process somehow or other." "322 According to this interpretation, "adopt" might mean "approve" or "endorse," as in "I adopt the Chairman's view of the issue." As

${ }^{317}$ United States of America Before the Federal Energy Regulatory Commission, Smart Grid Interoperability Standards, Docket No. RM11-2-000 27 (2011) (comments of Edison Elec. Inst.) (on file with the Harvard Law School Library) (suggesting that the "five families of standards" should be referred back for evaluation through improved NIST processes).

${ }^{318}$ Presumably, going forward, NIST would submit only those standards to FERC that are in the Catalog, "thereby assuring they have completed the SGIP life cycle and they have documented stakeholder support." FERC Technical Conference 2011, supra note 10 (statement of Ron Ambrosio), at 85-86.

${ }^{319}$ Quinn \& Reed, supra note 64, at 868.

${ }^{320}$ Lemley, supra note 186, at 1063-64.

${ }^{321}$ Opening Remarks to FERC Technical Conference 2011, supra note 10, at 6.

${ }^{322}$ FERC Technical Conference 2011, supra note 10 (statement of Ray Palmer), at 75. 
numerous commenters recognized, "adopt" could also mean "to select as basic or required," as, for example, "adopting" a textbook. FERC had suggested in 2009 that it could mandate standards for all domains of the grid and all participants, ${ }^{323}$ although, as noted above, it was not clear how it would enforce a mandate. ${ }^{324}$

Mandatory regulation was commenters' single greatest concern. The most frequent argument against it was that technical standards are typically adopted by the private sector in a "voluntary" process, not by "mandatory" federal rulemaking. ${ }^{325}$ PUCs also opposed mandatory standards because they, not FERC, have authority over distribution-level projects. ${ }^{326}$ One PUC believed FERC should merely encourage states to adopt standards and limit its role to securing compliance and enforcement once standards were in place. ${ }^{327} \mathrm{~A}$ FERC mandate would diminish PUCs' power, tilting regulatory authority toward FERC and away from them. ${ }^{328}$ States are virtually unwilling to cede any authority to FERC. In their comments, several states refused to endorse FERC support for the SGIP process, viewing even that relatively benign step as an intrusive federal mandate. States want guidance, but not if FERC tells them what to do.

State commenters even opposed a FERC mandate to comply with the standards in FERC's own area of exclusive jurisdiction, "interstate transmission of electric power, and regional and wholesale electricity markets." 329 They worried that standards might gain traction and work their way down to the local level. States are responsible for distribution-level activities, but that line will seem arbitrary when the issue under consideration is whether a smart meter can communicate with a device located on another part of the grid in another state.

Many commenters (including utilities and PUCs) supported their objections to FERC mandates by arguing that mandated standards preserve technolo-

${ }^{323}$ FERC Smart Grid Policy, supra note 23, II 22. Utilities' fears may stem in part from their experience with standards that transformed from voluntary to mandatory: Reliability standards morphed from guidelines of an informal, industry-centered regime to a mandatory regime that NERC enforces. That required an act of Congress. See 16 U.S.C. $\$ 8240(e)(3)$ (West 2012). The EISA, of course, gave FERC the authority to adopt mandatory standards within its jurisdictional area.

${ }^{324}$ U.S. Gov't Accountability OfFice, supra note 14, at 23-24 (discussing the lack of oversight authority).

${ }^{325}$ FERC Technical Conference 2011, supra note 10 (statement of George Arnold), at 16 ("In general, industry has a strong preference not to see standards adopted in regulation. This concern will naturally motivate many industry participants to cite reasons why FERC should not consider adopting these or other standards.").

${ }^{326}$ See, e.g., Empowering Consumers and Promoting Innovation through the Smart Grid: Hearing Before the Subcommittee on Technology and Innovation of the Committee on Science, Space, and Technology, 112th Cong. 5-6 (2011) (comments of Donna Nelson, Chairman, Public Utility Commission of Texas: "State commissions maintain jurisdiction over the distribution grid .... While some have advocated for a federal package of mandatory standards for adoption, we do not believe that the federal government should take action to mandate standards.")

${ }^{327}$ Smart Grid Interoperability Standards: United States of America Before the Federal Energy Regulatory Commission, Docket No. RM112-000 5-6 (2011) (comments of Colorado Public Utility Commission).

${ }_{328}$ BROWN ET AL., supra note 61, at 90 n.99.

32942 U.S.C.A. § 17385 (d) (West 2012). 
gies in amber, making them potentially obsolete later. Coming from utilities, the irony of this is palpable. Monopolists with control over the electricity system are arguing that setting standards will retard innovation by fostering the entrenchment of a status quo at some unspecified later date. ${ }^{330}$ If standards are not developed, the outcome is the status quo: utilities' continued economic dominance, in part due to government mandates that have fostered the existing electric system's development. In any event, if the NIST Catalog is a "toolkit," and not a "rulebook," this objection is less relevant. A state that believes the Catalog standards are not state-of-the-art is free to depart from them.

\section{FERC's Response}

FERC's response finessed the question about whether regulatory "adoption" is necessary to ensure that the Smart Grid is standardized and what steps FERC will take going forward. ${ }^{331}$ As counterintuitive as it might seem, FERC's decision may have been the best choice for the Smart Grid's future. Silence on many matters is indeed golden. One executive of an SDO observed, "the FERC decision is neither a rejection of the NIST consensus process nor the adoption of global standards for the Smart Grid." ${ }^{332}$

FERC has recognized, without saying so, that adoption will be unnecessary for most interoperability standards. ${ }^{333}$ There are compelling reasons why FERC need not substitute its judgment for that of the SGIP process. As Professor Mark Lemley has observed, "government agencies are generally composed of career public servants, not market participants [and] often do not involve the most qualified individuals in the industry at the moment in the standard-setting process." ${ }_{334} \mathrm{He}$ describes this as "an inherent danger of bureaucracy, particularly when it attempts to regulate such a fast-moving area of commerce as the Internet." ${ }_{335}$ Given the similarity of the Smart Grid to the Internet in size, scale, and dynamism, this is a serious concern here, too. The involvement of the

\footnotetext{
${ }^{330}$ BROWN ET AL., supra note 61, at 98 n.105.

${ }^{331}$ See, e.g., Chris King, FERC Says "Consensus" Lacking for Smart Grid Standards: What Consensus?, SMART GRID WATCH (Jul. 27, 2011), http://www.emeter.com/smart-grid-watch/2011/ ferc-says-consensus-lacking-for-smart-grid-standards-what-consensus/ ("[S]aying that "consensus has not been reached' alone is too vague without saying consensus on what."); Jesse Berst, Smart Grid Standards Slowdown Puts Utilities at Risk, SmartGridNews.com (Jul. 26, 2011), http://www.smartgridnews.com/artman/publish/Technologies_Standards/Smart-grid-standardsslowdown-puts-utilities-at-risk-3863.html ("FERC also failed to give any guidance on what happens next. Whether the National Institute of Standards and Technology (NIST) should continue to work on the standards. Whether and when FERC should reconsider them. Whether we should just give up and pack it in.").

${ }^{332}$ NEMA Responds to FERC Ruling on Smart Grid Standards, NAT'L ELEC. MFrs. Ass'N (Jul. 21, 2011), http://www.nema.org/News/Pages/NEMA-Responds-to-FERC-Ruling-on-SmartGrid-Standards.aspx.

${ }^{333}$ This is consistent with the comments of NIST Administrator Arnold at the technical conference. FERC Technical Conference 2011, supra note 10 (statement of George Arnold), at 8 ("I recommend that the Commission consider taking a different approach that focuses on the question of whether regulatory adoption is needed to insure use of the standards by industry to achieve smart grid interoperability.").

${ }^{334}$ Lemley, supra note 186 , at 1063.

${ }^{335}$ Id.
} 
states adds a layer of complexity. FERC would face serious challenges if it tried to keep track of the electricity standards "market": what 51 different jurisdictions are doing at any given moment. ${ }^{336}$

Instead, FERC is now able to play a more ideal role for a central government actor in a vibrant and functioning federalist system of standard-setting. The federal government is at its best in standard-setting when it brokers a collaboration of collaborations in which participants without common understanding can work together. ${ }^{337}$ It is a creative and dynamic approach that we might think of as government-led crowdsourcing. ${ }^{338}$ As one SDO executive observed, the "[c]atalog of Standards provides the perfect venue to conform to the FERC order." 339 Congress believed mandated standards were necessary to promote rapid standard-setting and to overcome coordination difficulties. However, acceptance by the community that implements them - the touchstone of all consensus standards - does not flow from a regulator's endorsement, but from use of standards in practice.

Agency rulemaking is inconsistent with that tradition. It is also an inefficient means for establishing standards. Standards are dynamic instruments, and if a standard imposed by rule did not work in practice, the only recourse would be a new rule. The threshold for considering a revised rule would be different (the agency could refuse to revisit its decision), and, of course, the new rule would be subject to all of the procedural requirements, and potential for delay, as the original one. The principal check on a suboptimal decision by an agency is judicial review, which employs standards that focus on whether a court should substitute its judgment for that of the agency, not on the standards' technical merits.

With hundreds of standards to be evaluated, setting standards by rule introduces the potential for high transaction costs and delay. ${ }^{340}$ Approval of the first five standards encountered strong opposition, so it is entirely foreseeable that powerful stakeholders would attempt to tie up standards in costly litigation that could potentially keep them from becoming final for years. Such uncer-

${ }^{336}$ U.S. Gov't ACCOUnTABILITy OfFICE, supra note 14, at 21 ("Unless FERC and other regulators have a good understanding of whether utilities and manufacturers are following smart grid standards, it will be difficult to know whether a voluntary approach to standards setting is effective or if changes are needed.").

${ }^{337}$ FERC Standards Order, supra note 16, II 10 (noting that the SGIP "brings together smart grid stakeholders from numerous industries and areas of expertise to guide the development of smart grid interoperability standards").

${ }^{338}$ Cf. Kara Platoni, Tide Pools and Terrorists, Stan. Mag. (Jan.-Feb. 2012), available at http://alumni.stanford.edu/get/page/magazine/article/?article_id=46396 ("Instead of relying on a centralized brain or controller for everything, you farm out the responsibility of searching for and responding to changes in the environment to many, many different agents.").

${ }^{339}$ NAt'l Elec. Mrrs. Ass'N, supra note 332.

${ }^{340}$ FERC, supra note 205, at slide 5 ("Because the first group of standards is not likely to address all key priorities identified by NIST and the Commission, Staff anticipates continuing development of new standards and modification to existing standards to address these priorities, with additional notifications from NIST on a regular basis. As such, staff recommends that the Commission periodically initiate rulemaking proceedings in response to postings of new smart grid interoperability standards by NIST.”). 
tainty would mean that projects would proceed without standards, which could jeopardize interoperability. ${ }^{341}$

Given the rulemaking process's inefficiencies, the SGIP process should yield quicker results. Without federal rules, NIST cannot require adoption of standards, but the Catalog will send strong signals about the preferences of large numbers of stakeholders. Utilities and PUCs have relied on voluntary consensus standards for decades and can do so here. Some already have, such as the three major California utilities implementing the Green Button Initiative. This shows how the interoperability "toolkit" may find repeated use in the future, and also demonstrates, as noted above, how utilities may support the SGIP process. The force of the standards may eventually crowd out objectors.

\section{The Future of Standards - Adoption at the State Level}

Where does this leave the states? After the FERC order, they do not have to adopt standards in the Catalog, but they are free to do so. ${ }^{342}$ They can review projects under their normal criteria, and deem imprudent any project that does not follow applicable standards, disallowing cost recovery. ${ }^{343}$ Some states have indicated that they want utilities to use standards as a source of best practices. As the Catalog grows, the states may rely upon it as a valuable technical resource. Proceeding without FERC's approval signals that the standards' credibility, like that of other voluntary consensus standards, will derive from their use in Smart Grid projects.

By not adopting the standards, FERC left the distribution of jurisdiction over the electric grid unchanged and postponed perhaps forever the threat of a federal/state power struggle over the Smart Grid's foundation. This decision signals that suggesting FERC could affect the retail electricity market with Smart Grid standards was overreaching. By declining to mandate standards, FERC has neither regulated nor ceded the prospect of a regulatory role in the distribution side of the Smart Grid. It retains its authority under the EISA, and in limited instances, FERC can take discrete actions on standards to preserve reliability and ensure cybersecurity.

In the near-term, NIST will add more standards to the Catalog. States should become more comfortable with the standards as they approve projects that rely on them. Other events may provide additional reasons to use the standards. States' energy and climate change policies (for example, the California and Texas data availability requirements that led to the Green Button Initiative)

${ }^{341}$ FERC Technical Conference 2011, supra note 10 (statement of George Arnold), at 7-8 ("By the time the Commission adopts rules on the many individual standards in the NIST Framework, which could take years, significant investments in grid modernization will already have occurred, and there is the danger that a lot of investment will continue to be made in proprietary systems that do not support smart grid interoperability.").

${ }^{342}$ BROwN ET AL., supra note 61, at 90; NIST SGIP, supra note 265 ("[I]mplementers may have good reasons to choose something not listed. However, using an entry in the catalog may help explain choices to others.")

${ }^{343}$ BROWN ET AL., supra note 61, at 90. 
may drive use of the standards. The Smart Grid will grow and evolve, without mandatory standards. FERC can limit its role to resolving conflicts between states if the states adopt incompatible technologies and standards.

FERC can step in if necessary in three distinct cases: when it sees states' actions leading to balkanization of Smart Grid standards, when it believes economic interests unfairly dominated the SGIP process, and when it believes national objectives such as cybersecurity have not been achieved. ${ }^{344}$ Think of this as a dynamic fine-tuning federalism. The large and diverse group of Smart Grid stakeholders is defining what the Smart Grid is in real time, with concurrent decisions about law and technology. ${ }^{345}$ Smartness in this complex, multifaceted environment, with its many uncertainties, demands that regulators adapt to changing ideas of how to govern the Smart Grid. Smart Grid federalism can be smart: an open, evolving relationship, not a static entity. In a sense, the dynamism called for here compares to climate change federalism, where the relationship between states and the federal government has evolved as states innovate to respond to climate concerns and federal activity promotes uniform solutions. ${ }^{346}$ FERC's action, and the continuation of the SGIP process, will allow for standards to be developed while striking a balance between necessary caution about upending the electricity system all at once and doing what will eventually be essential to promote innovation.

\section{Conclusion}

The need for Smart Grid interoperability standards is obvious, and some support from the federal government in developing them is necessary. Yet FERC's order appeared to reject a set of standards that had widespread approval. That decision, this Article argues, was proper. A flexible approach that allows the Smart Grid to evolve, just as the Internet developed, will yield better results than trying to dictate mandatory standards today.

The significance of NIST's standard-setting efforts cannot be underestimated. When the Smart Grid's history is written, standards in the NIST Framework such as SEP 2.0 and early stage uses of the interoperability standards such as the Green Button Initiative will be seen as the forerunners of many more

${ }^{344}$ At least one state that opposed mandatory standards suggested they might be necessary in the third case listed here. See United States of America Before the Federal Energy Regulatory Commission, Smart Grid Interoperability Standards, Docket No. RM11-2-000 1-3, 5-6 (2011) (initial comments of Michigan Public Service Commission) (on file with Harvard Law School Library) (opposing enforceable standards, with the exception of limited areas such as those needed to ensure cybersecurity).

${ }^{345}$ LBNL SMART GRID 101 CH. 1-3, supra note 19, at 16 ("[A]lmost all of the benefits require concurrent implementation of policy, rate, and technology options.").

${ }^{346}$ See Alexandra B. Klass, State Innovation and Preemption: Lessons From State Climate Change Efforts, 41 Loy. L.A. L. REv. 1653 (2008) for a discussion of dynamism under tension between the states and federal government in fashioning climate change solutions"; see also Ann E. Carlson, Iterative Federalism and Climate Change, 103 Nw. U. L. REv. 1097, 1100 (2009) (discussing "iterative federalism" whereby "federal law consciously designates a particular and distinct state or group of states to regulate and relies on that regulatory arrangement to enhance compliance with federal standards"). 
robust and useful uses of energy information. The SGIP process will be hailed as foundational to a wide range of energy saving technologies, and the standards will be honored as landmarks of the modern technology age.

An expanded federal role may be necessary in the long run. Federal preemption with an open access law may eventually be required to match the Smart Grid's national scale and promote new firms and applications. Yet for now, relying on the states' authority over local distribution is essential. The shift to a Smart Grid will not occur instantaneously. New firms that would seek to use local distribution wires largely do not yet exist. Profound near-term regulatory change would be like swapping pilots in an airplane at 30,000 feet. One can envision that shifting market conditions may motivate utilities to seek change, just as shifting market conditions for phone service in the 1990s, in particular the rise of cheap long distance calling, led phone companies to seek change by federal regulation. ${ }^{347}$ For now, that is years away. Adopting standards today would require making a lasting statement about the federal-state relationship at a time when preemption is not yet warranted.

In the current climate, it is difficult for FERC to expand its power. Later, it may not be. After circumstances change, a decision about adopting standards may do no more than ratify an existing consensus, instead of forcing it on stakeholders today. However, FERC's decision puts off this confrontation until a point when it may not appear to be a confrontation at all. That is profoundly smart.

${ }^{347}$ See, e.g., Nicholas Economides, Telecommunications Regulation: An Introduction 45, 55-56, in The Limits and Complexity of Organizations (Richard R. Nelson, ed. 2005), available at http://www.stern.nyu.edu/networks/Telecommunications_Regulation.pdf.

Utilities have led industry transitions before. In the early 20 th century, utilities supported the move from municipal franchises to state regulation. Ashley C. Brown, The Structure and Process for Regulation of the Electricity Industry in the United States 1-2 (2005), available at http://www.hks.harvard.edu/hepg/brown_papers/ABrown_IndiaPlanning_1-05.pdf. Although it may appear unlikely today, if market conditions change, utilities may eventually prompt a similar move to federal Smart Grid regulation. 